\title{
A Comparative Examination of the Published Editions of Alexander Glazunov's Concerto in E-flat Major for Alto Saxophone and String Orchestra, Op. 109
}

Christopher D. Mickel

West Virginia University

Follow this and additional works at: https://researchrepository.wvu.edu/etd

\section{Recommended Citation}

Mickel, Christopher D., "A Comparative Examination of the Published Editions of Alexander Glazunov's Concerto in E-flat Major for Alto Saxophone and String Orchestra, Op. 109" (2011). Graduate Theses, Dissertations, and Problem Reports. 3038.

https://researchrepository.wvu.edu/etd/3038

This Dissertation is protected by copyright and/or related rights. It has been brought to you by the The Research Repository @ WVU with permission from the rights-holder(s). You are free to use this Dissertation in any way that is permitted by the copyright and related rights legislation that applies to your use. For other uses you must obtain permission from the rights-holder(s) directly, unless additional rights are indicated by a Creative Commons license in the record and/ or on the work itself. This Dissertation has been accepted for inclusion in WVU Graduate Theses, Dissertations, and Problem Reports collection by an authorized administrator of The Research Repository @ WVU.

For more information, please contact researchrepository@mail.wvu.edu. 
A Comparative Examination of the Published Editions of Alexander Glazunov's Concerto in E-flat Major for Alto Saxophone and String Orchestra, Op. 109

\author{
Christopher D. Mickel
}

\author{
Doctoral Research Project Presented to the \\ College of Crative Arts \\ at West Virginia University \\ in partial fullfillment of the requirements \\ for the degree of
}

Doctor of Musical Arts
in
Saxophone Performance

Francesca Arnone, D.M.A., chair

Michael Ibrahim, D.M.A.

Andrew Kohn, Ph.D.

Kathleen Shannon, D.M.A.

Linda Milian, M.F.A.

Division of Music

Morgantown, West Virginia

2011 


\title{
Abstract \\ A Comparative Examination of the Published Editions of Alexander Glazunov's Concerto in E-flat Major for Alto Saxophone and String Orchestra, Op. 109
}

\author{
Christopher D. Mickel
}

\begin{abstract}
Alexander Glazunov’s Concerto in E-flat Major for Alto Saxophone and String Orchestra of 1934, written for virtuoso saxophonist Sigurd M. Rascher, is one of the most significant works within the saxophone literature. This document provides historical details of Glazunov's work, including a discussion of the cirumstances leading to its composition, while comparing the editions currently available to define a clearer understanding of the work and the composer's intentions.

First published in 1936 by Alphonse Leduc, this French edition has been the sole version available. However, in late 2010, with the aid of Sigurd Rascher's daughter Carina, the German company Bärenreiter published a scholarly edition of the work. This paper features a comparative analysis of the two editions supported by numerous musical examples. In the time between the initial composition of the concerto and its publication, Glazunov made several revisions to the work which were not included in its first publication. This paper examines the discrepancies between the autographed manuscript and the published editions as well as the correspondence between Glazunov and Rascher in which Glazunov discusses his edits. Citing the Concerto's pedagogical and performance resources, this paper also considers a Music Minus One edition intended for practice as well as an alternate cadenza composed by Christian Lauba.

This paper contains concise accounts of the composition and publication history of the Concerto by drawing upon the significant scholarly research relating to it. The author concludes that by considering the different editions of the work as well as other performance resources related to the work saxophonists will present new interpretations of the Concerto. This research will assist in reinvigorating this well-established work while providing a single, comprehensive source.
\end{abstract}




\section{Dedication}

This document is dedicated to the memory of my late father, Cleo David Mickel.

\section{Acknowledgments}

This research would not have come to fruition if not for the generous assistance, knowledgable guidance, and encouraging support of several people. First of all, I would like to thank my committee members: Francesca Arnone, Michael Ibrahim, Andrew Kohn, Kathleen Shannon, and Linda Milian for their patience, guidance, and support throughout my studies at West Virginia University; especially Dr. Ibrahim and Dr. Arnone. Their insight and experience proved to be invaluable in the completion of this research.

I would also like to extend my thanks to Carina Rascher, Christian Lauba, and Douglas O’Connor. The information I gained through correspondance with them was extremely helpful. I would also like to thank Petra Woodfull-Harris at Bärenreiter who aided in the completion of this research by sending me advance copies of the scores to the Concerto several months before Bärenreiter's edition was commercially available. Further thanks are extended to Dr. David Wright for his guidance at the beginning of my doctoral studies.

I would like to send my deepest thanks to my family, especially my mother, Patricia G. Mickel and my Grandfather, Boyd V. Gandee. My doctoral studies would not have been possible without them. Lastly, a special thanks to Denise Peters, for her loving encouragement and support. 


\section{Table of Contents}

Abstract $\quad$ ii

Dedication $\quad$ iii

Acknowledgements $\quad$ iii

Table of Contents $\quad$ iv

List of Tables $\quad$ V

List of Figures $\quad$ V

Chapter 1: Introduction $\quad 1$

Discussion of Research Methodology 2

Chapter 2: Historical Background $\quad 3$

Initial Composition 3

For whom was the Concerto Written?

The Premiere Performance 6

André Petiot $\quad 7$

Chapter 3: Comparative Analysis $\quad 9$

Contrasting the Leduc and Bärenreiter Editions $\quad 9$

The Saxophone Solo Part

The Saxophone Solo Part: Section One 12

The Saxophone Solo Part: Section Two 19

The Saxophone Solo Part: Section Three $\quad 30$

The Orchestra Score and the Piano Reduction 49

Chapter 4: Conclusions $\quad 51$

Summary of Differences between the Concerto's Two Editions 51

The Orchestra Score $\quad 54$

Other Resources Related to Glazunov’s Concerto 56

Closing Remarks 58

Appendix: Variance in Slur Placement in Measures

179 through the Downbeat of measure 189

$\begin{array}{ll}\text { Bibliography } & 67\end{array}$ 


\section{List of Tables}

Table 3.1. Bärenreiter articulations: attacks and releases

Table 3.2: Differences in slur placement

\section{List of Figures}

Figure 3.1. Alexander Glazunov, Concerto in E-flat Major for Alto Saxophone and String Orchestra, Op. 109, Leduc edition measure 108 - 111. Placement of phrase markings.

Figure 3.2. Alexander Glazunov, Concerto in E-flat Major for Alto Saxophone and String Orchestra, Op. 109, Bärenreiter edition measure 108 - 111. Placement of phrase markings.

Figure 3.3. Alexander Glazunov, Concerto in E-flat Major for Alto Saxophone and String Orchestra, Op. 109, measures 11 - 26. Articulations and placement of phrase markings.

Figure 3.4. Alexander Glazunov, Concerto in E-flat Major for Alto Saxophone and String Orchestra, Op. 109, measures 27 - 36. Articulations and placement of phrase markings.

Figure 3.5. Alexander Glazunov, Concerto in E-flat Major for Alto Saxophone and String Orchestra, Op. 109, measures 40 - 52. Articulations and placement of phrase markings.

Figure 3.6. Alexander Glazunov, Concerto in E-flat Major for Alto Saxophone and String Orchestra, Op. 109, measures 59 - 61. Articulations and placement of phrase markings.

Figure 3.7. Alexander Glazunov, Concerto in E-flat Major for Alto Saxophone and String Orchestra, Op. 109, measures 81 - 103. Articulations and placement of phrase markings.

Figure 3.8. Alexander Glazunov, Concerto in E-flat Major for Alto Saxophone and String Orchestra, Op. 109, measures 104 - 119. Articulations and placement of phrase markings.

Figure 3.9. Alexander Glazunov, Concerto in E-flat Major for Alto Saxophone and String Orchestra, Op. 109, measures 123 - 141. Articulations and placement of phrase markings.

Figure 3.10. Alexander Glazunov, Concerto in E-flat Major for Alto Saxophone and String Orchestra, Op. 109, measures 145 - 154. Articulations and placement of phrase markings.

Figure 3.11. Alexander Glazunov, Concerto in E-flat Major for Alto Saxophone and String Orchestra, Op. 109, measures 155 - 156. Articulations and placement of phrase markings.

Figure 3.11. Alexander Glazunov, Concerto in E-flat Major for Alto Saxophone and String Orchestra, Op. 109, measures 159 - 160. Articulations and placement of phrase markings. 
Figure 3.13. Alexander Glazunov, Concerto in E-flat Major for Alto Saxophone and String Orchestra, Op. 109, measures 163 - 164. The cadenza presented in the Leduc edition and the second cadenza presented in the Bärenreiter edition.

Figure 3.14. Alexander Glazunov, Concerto in E-flat Major for Alto Saxophone and String Orchestra, Op. 109, measures 163 - 164. The first cadenza presented in the Bärenreiter edition.

Figure 3.15. Alexander Glazunov, Concerto in E-flat Major for Alto Saxophone and String Orchestra, Op. 109, measures $163-164$. The third cadenza in the Bärenreiter edition.

Figure 3.16. Alexander Glazunov, Concerto in E-flat Major for Alto Saxophone and String Orchestra, Op. 109, measures $176-178$. Variation in melodic content.

Figure 3.17. Alexander Glazunov, Concerto in E-flat Major for Alto Saxophone and String Orchestra, Op. 109, measures $179-189$. Articulations and placement of phrase markings.

Figure 3.18. Alexander Glazunov, Concerto in E-flat Major for Alto Saxophone and String Orchestra, Op. 109, measures 193 - 201. Articulations and placement of phrase markings.

Figure 3.19. Alexander Glazunov, Concerto in E-flat Major for Alto Saxophone and String Orchestra, Op. 109, measures $201-208$. Articulations and placement of phrase markings.

Figure 3.20. Alexander Glazunov, Concerto in E-flat Major for Alto Saxophone and String Orchestra, Op. 109, measures 209 - 216. Articulations and placement of phrase markings.

Figure 3.21. Alexander Glazunov, Concerto in E-flat Major for Alto Saxophone and String Orchestra, Op. 109, measures 217 - 224. Articulations and placement of phrase markings.

Figure 3.22. Alexander Glazunov, Concerto in E-flat Major for Alto Saxophone and String Orchestra, Op. 109, measures 225 - 235. Articulations and placement of phrase markings.

Figure 3.23. Alexander Glazunov, Concerto in E-flat Major for Alto Saxophone and String Orchestra, Op. 109, measures 236 - 253. Articulations and placement of phrase markings.

Figure 3.24. Alexander Glazunov, Concerto in E-flat Major for Alto Saxophone and String Orchestra, Op. 109, measures 249 - 253. Articulations and placement of phrase markings.

Figure 3.25. Alexander Glazunov, Concerto in E-flat Major for Alto Saxophone and String Orchestra, Op. 109, measures 259 - 268. Articulations and placement of phrase markings.

Figure 3.26. Alexander Glazunov, Concerto in E-flat Major for Alto Saxophone and String Orchestra, Op. 109, measures 269 - 267. Articulations and placement of phrase markings

Figure 3.27. Alexander Glazunov, Concerto in E-flat Major for Alto Saxophone and String Orchestra, Op. 109, measures $281-285$. Articulations and placement of phrase markings. 
Figure 3.28. Alexander Glazunov, Concerto in E-flat Major for Alto Saxophone and String Orchestra, Op. 109, measures 289 - 293. Dynamic markings.

Figure 3.29. Alexander Glazunov, Concerto in E-flat Major for Alto Saxophone and String Orchestra, Op. 109, measures 293 - 300. Articulations and placement of phrase markings.

Figure 3.30. Alexander Glazunov, Concerto in E-flat Major for Alto Saxophone and String Orchestra, Op. 109, measures 311 - 312. Articulations and placement of phrase markings.

Figure 3.31. Alexander Glazunov, Concerto in E-flat Major for Alto Saxophone and String Orchestra, Op. 109, measures 316 - 320. Articulations and placement of phrase markings.

Figure 3.32. Alexander Glazunov, Concerto in E-flat Major for Alto Saxophone and String Orchestra, Op. 109, measures 324 - 328. Articulations, placement of phrase markings, and altissimo notes.

Figure 3.33. Alexander Glazunov, Concerto in E-flat Major for Alto Saxophone and String Orchestra, Op. 109, measures 328 - 329. The final gesture.

Figure 4.1. Alexander Glazunov, Concerto in E-flat Major for Alto Saxophone and String Orchestra, Op. 109, measures 327 - 329. Revision made by Glazunov, October $2^{\text {nd }}, 1934$.

Figure 4.2. Alexander Glazunov, Concerto in E-flat Major for Alto Saxophone and String Orchestra, Op. 109, measures 165 - 169. Cello part as it appears in the Leduc and Bärenreiter editions.

Figure 4.3. Alexander Glazunov, Concerto in E-flat Major for Alto Saxophone and String Orchestra, Op. 109, measures 165 - 169. Cello part as it appears in the autographed score.

Figure 4.4. Alexander Glazunov, Concerto in E-flat Major for Alto Saxophone and String Orchestra, Op. 109, measures 169 - 178. Cello part as it appears in the Leduc and Bärenreiter editions. 


\section{Chapter 1: Introduction}

\section{Alexander Glazunov’s Concerto in E-flat Major for Alto Saxophone and String}

Orchestra is one of the most significant works within the saxophone literature. First published in 1936 by Alphonse Leduc, this French edition has been the sole version available. However, in late 2010, the German company Bärenreiter published a new scholarly edition of the work.

German saxophone virtuoso Sigurd M. Rascher (1907 - 2001), for whom the Concerto was composed, gave its premiere in 1934, two years before its publication by Alphonse Leduc. In the premiere performance, Rascher played from Glazounov’s original manuscript. According to Rascher, there are differences between this manuscript and the Alphonse Leduc edition. ${ }^{1}$ The new edition by Bärenreiter has been edited by Rascher’s daughter, Carina. Carina, like her father, is a prominent saxophonist and pedagogue. As a result of her work, this new edition makes use of the melodic contoures and durations present in Glazounov’s autographed manuscript and the phrasing, articulation, dynamic indications, the styles of note attacks of certain notes, indication of specific fingerings, and breath marks which represents her father's approach to performing the work.

Comparative examination between these two published editions and the manuscript of Glazounov’s Concerto substantiates the need for this research by addressing four primary concerns: to provide historical background relating to the composition of the work, to identify differences through a comparative analysis of the Alphonse Leduc edition and the new Bärenreiter edition, to provide explanations for the differences between the editions and how

1. Sigurd M. Rascher, “Alexander Glazunov: Concerto pour Saxophone Alto avec l'orchestre de cordes,” Saxophone Symposium, Volume XIII, No.3 (Summer, 1988), 16-19. 
they relate to the autographed manuscript, and to discuss and evaluate other musical resources related to this work.

\section{Discussion of Research Methodology}

The research methodology involves the study of the history of The Concerto, and a comparative analysis of the Alphonse Leduc edition and the new Bärenreiter edition. For the discussion of the historical background, the author has surveyed the available literature to provide an accurate account of the circumstances regarding the compositional process of this work. There has been disagreement regarding the circumstances under which it was composed, for whom it was composed, its premiere, and subsequent publication. This document will clarify many of the discrepancies regarding the work’s origin.

After providing an accurate discussion of the historical background of this work, the author includes a comparative analysis of the published editions of this Concerto, the Alphonse Leduc edition and the Bärenreiter edition, in order to determine the differences between them. To propose possible explanations for these variations, the author will addresses the significance of the autographed manuscript followed by a discussion of more recent resources related to Glazunov's work. 


\section{Chapter 2: Historical Background}

\section{Initial Composition}

The Concerto was composed in 1934. Sigurd Rascher, who was very vocal about promoting the saxophone, was the initial catalyst for the composition of this work. The circumstances relating to the composition of the Concerto are closely related to the premiere performance of Glazunov's other saxophone work, the Saxophone Quartet, Op. 109. The Quartet was premiered in 1932, the same year of its composition, by Marcel Mule’s saxophone quartet, the Quatuor de le Garde Republicane.

The premiere of the Quartet was a private performance held in Paris between December 9 and 16, 1932; Glazunov invited a few friends and personalities. ${ }^{2}$ Among those in attendance was Sigurd Rascher whose recollection of the performance is as follows:

As I was just in Paris, I had to hear it. I still remember the homogeneous sound of the four saxophones. So enthusiastic was I that I applauded until my hands were red. Here was a real ovation, in its persistent liveliness obviously not only aimed at the performers, but more so yet at the composer: a tall, lightly stooping gentleman with white hair, who stood quietly in the auditorium. With a benevolent smile he thanked for the applause. In his life he had seen many ovations; this one, however, was different: his friends honored him. ${ }^{3}$

It was at this performance where the association between Rascher and Glazunov began. The performance was very moving for Rascher, as he recalls: “Overflowing with enthusiasm, eventually even I made it into the artists’ room. I had difficulties expressing myself in common language, so I held the master’s hand an asked simply, 'May I play for you?’ „4 Rascher then met with Glazunov and played for him. It was at this meeting that Rascher carefully suggested

\footnotetext{
2Jacques, Charles. “Dossier Glazounov.” Translated by Bernard Savoie. Saxophone Symposium, Vol. XIII, No. 3 (Summer 1988): 20.

${ }^{3}$ Sigurd M. Rascher, “Alexander Glazunov: Concerto pour Saxophone avec l'orchestre de cordes.” Saxophone Symposium, Vol. XIII, No.2 (Spring 1988): 17.

${ }^{4}$ Rascher, “Alexander Glazunov,” 16.
} 
that Glazunov compose a concerto; Glazunov responded: “Oui, for such a musician I will write one.” Glazunov then suggested that Rascher see him again within the next few weeks. ${ }^{5}$

According to his correspondence with his colleague Maximilian Oseevich Steinberg, Glazunov began work on the Concerto early in the spring of 1934. In a letter dated March 17 1934, Glazunov stated that he had begun composing the Concerto “...under the influences of attacks rather than requests from the Danish saxophonist Sigurd Rascher.” ${ }^{6}$ In a letter dated April 4 1934, Glazunov told Steinberg that the Conceto was finished. ${ }^{7}$

Following its completion, Rascher received word that the Concerto was finished in sketch form; as Rascher recalls: "Soon thereafter in Copenhagen, where I lived at the time, word reached me that the Concerto was completed in sketches. Not long afterward, I received the solo part.”8 Rascher again visited Glazunov and played the work for him in order to receive the composer's feedback. Rascher recalls this meeting: “These were unforgettable hours: even today, more than half a century later, not only what was said about the music is clear in my memory, but also the master's voice, his facial expression, and even the furnishings of the music room."9

Glazunov gave Rascher the completed autographed score. Rascher recalls receiving it: "In order to enable me to perform the Concerto, the composer gave me a score of 56 pages...”"10 It is unclear as to when Rascher received the completed autographed score; however, the

${ }^{5}$ Rascher, “Alexander Glazunov,” 16.

${ }^{6}$ André Sobchenko. "Letters from Glazunov: 'The Saxophone Concerto Years'.” The Saxophone Journal (September/October 1997): 68.

${ }^{7}$ Sobchenko, "Letters", 68.

${ }^{8}$ Rascher, "Alexander Glazunov,” 16.

${ }^{9}$ Rascher, "Alexander Glazunov,” 16.

${ }^{10}$ Rascher, “Alexander Glazunov,” 16. 
Concerto was completed by early May of 1934 . This is supported by the inscription on the final page of the autographed score that reads: "4. May 1934, Boulogne s/S. Alexander Glazunov."”11

\section{For whom was the Concerto Written?}

There have been misconceptions regarding the composition of Glazunov's work that can be traced to a letter written by Gilbert Leduc dated January 20, $1960 .{ }^{12}$ Leduc's letter contains inaccuracies regarding the genesis of the work. In this letter, Leduc states "It was the last work written by the great master Glazunov in Paris in 1936." ${ }^{\prime 3}$ This is clearly false as Glazunov himself inscribed the date of May 4, 1934 on the final page of the autographed manuscript. Furthermore, Glazunov's correspondence with Steinberg states that the work was completed by April of 1934.

Leduc goes on to state, “....and it was Mr. Alphonse Leduc who caused the writing of Glazonov's Concerto..."14; again, this is not accurate. Rascher's recollection of the events which led to the composition of the work, as well as Glazunov's letters to Steinberg, clearly identifies Rascher as the inspriation for the work. Furthermore, the first page of the autographed manuscript bears the dedication: "A Sigurd M. Rascher." ${ }^{15}$ As Rascher informed his daughter, Carina, Glazunov made these inscriptions in her father's presence. ${ }^{16}$ Lastly, Glazunov discusses his difficulty obtaining apublisher for the Concerto in two letters written to Rascher. In the first letter dated September 2, 1934 Glazunov wrote "As yet I have no publisher for my work” and the

\footnotetext{
${ }^{11}$ Rascher, “Alexander Glazunov,” 16.

${ }^{12}$ Gilbert Leduc is the son of Alphonse Leduc who was the founder of the firm which published the Concerto in 1936.

${ }^{13}$ Charles, "Dossier," 21.

${ }^{14}$ Charles, "Dossier," 21.

${ }^{15}$ Rascher, “Alexander Glazunov,” 17.

${ }^{16}$ Alexander Glazunov, Concerto In E-Flat Major for Alto Saxophone and String Orchestra (Kassel, Germany: Bärenreiter, 2010), XIII.
} 
second dated September 11, 1934 where Glazunov stated "Unfortunately I have as yet not found a publisher.” Alphonse Leduc could not have comissioned or otherwise "caused the writing of" the work since Glazunov stated in the months after he finished composing it that he could not find a publisher. ${ }^{17}$

This information in Gilbert Leduc's 1960 letter regarding Glazunov’s Concerto is false, as the evidence against it is clear. The work was composed in 1934, not 1936, and Alphonse Leduc was not involved until its publication in 1936.

\section{The Premiere Performance}

Rascher and Marcel Mule gave the first performances of the Concerto, both of whom recall giving the premiere performance. Glazunov was very excited that his work was going to be performed, and he acknowledged that Rascher and Mule would give the first performances. In a letter to Steinberg dated June 4, 1934, Glazunov stated: "I completed the Concerto for saxophone, both the score and clavier, and most likely I will hear performances within days by the Frenchmen Mule and the Danish Saxophonist Rascher.”18 These performances would not take place until the following autumn and winter.

Glazunov discussed the premiere performance in a letter to Steinberg dated November 21, 1934: “The Danish Saxophonist Rascher, with very good, indeed tremendous technique, will perform it."19 Rascher performed the world premiere on November 26, 1934, in the Church of St. Nicholas in Nyköping, Sweden with the Norrköping Symphony Orchestra with Tord Benner conducting. The work was performed again the next day in Norrköping. ${ }^{20}$ Glazunov supports

\footnotetext{
${ }^{17}$ Charles, “Dossier,” 22.

18 Sobchenko, "Letters," 68.

19 Sobchenko, “Letters,” 69.

${ }^{20}$ Glazunov, Concerto in E-Flat Major, XIII.
} 
this in another letter to Steinberg dated December 5, 1934: “The Saxophone Concerto was

premiered twice by Sigurd Rascher in the two largest cities of Sweden. Next year I will hear it in Paris."21

In an interview with the prominent American saxophonist and pedagogue, Eugene

Rousseau $^{22}$, Mule recalls giving the premiere performance.

Mule - Glazunov had written the Quartet, Op. 109 for us prior to composing the Concerto. At any rate, I read the Concerto with Glazunov at the piano; and he must have liked it, for it was a month or two later that I performed the Concerto for the French radio.

Rousseau - Then your performance of Glazunov's Concerto over French Radio was prior to the first performance given by Sigurd Rascher, for whom it had been composed?

Mule - Yes, that is correct. ${ }^{23}$

This performance, which was the French premiere, took place on January 20, 1935, at Radio

Colonial in Paris, with Marcel Mule as soloist and Henry Tomasi conducting, two months after

Rascher's world premiere. $^{24}$

Glazunov was well aware of ongoing performances of the Concerto as he remained in contact with Rascher. It is unclear as to whether Glazunov ever heard the work. He died on March 21, 1936, and there is no further information indicating if the composer was ever present at a performance. $^{25}$

\section{André Petiot}

The name André Petiot appears as a co-composer on the saxophone solo part and the piano reduction of Leduc's edition of Glazunov's work. It is quite clear that Petiot had no

\footnotetext{
${ }^{21}$ Sobchenko, “Letters”, 69

${ }^{22}$ Eugene Rousseau is a student of Marcel Mule. Marcel Mule would not have known of Rascher’s

${ }^{23}$ Charles, "Dossier", 23

${ }^{24}$ Glazunov, Concerto in E-Flat Major, XIII

${ }^{25}$ Sobchenko, "Letters”, 69
} performances of the Concerto. 
involvement in the compositional process; in all of the archival letters recorded, Glazunov never mentioned working with a colleague. ${ }^{26}$

Petiot's name was credited as a co-composer to make it possible for Glazunov to receive French royalties for his work. At the time, the Soviet government had ceased to pay royalties on French works in the Soviet Union and in retaliation the French government had done the same for Russian works. ${ }^{27}$ Since the French government ceased to pay royalties on Russian works in France, André Petiot accepted the figure of co-author in order to serve as a liaison for the royalty payments by SACEM (Société des auteurs, compositeurs et éditeurs de musique ${ }^{28}$ ) to Glazunov. $^{29}$ Marcel Mule reported that Alphonse Leduc had mentioned that it was a matter of copyright. ${ }^{30}$ The publisher visited Glazunov many times to make arrangements for the composer to receive royalty payments. However, it is unlikely that Glazunov benefited much from this arrangement because he died in less than a month after the work was published. ${ }^{31}$

${ }^{26}$ Sobchenko, "Letters," 69.

${ }^{27}$ Charles, "Dossier," 23.

${ }^{28}$ Société des auteurs, compositeurs et éditeurs de musique (SACEM) is a French professional association collecting payments of artists' rights and distributing the rights to the original songwriters, composers and music publishers.

${ }^{29}$ Charles, "Dossier," 23.

${ }^{30}$ Charles, "Dossier," 23.

${ }^{31}$ Charles, "Dossier," 23. 


\section{Chapter 3: Comparative Analysis}

\section{Contrasting the Leduc and Bärenreiter Editions}

\section{The Saxophone Solo Part}

The most significant differences between the Leduc edition and the Bärenreiter edition of Glazunov's concerto lie in the saxophone solo part. ${ }^{32}$ Of these differences, the most apparent are related to phrasing. The Leduc edition employs phrase markings over smaller groupings of pitches (Figure 3.1), the markings are used to indicate slurs and not the overall phrase. The French edition breaks the phrase into multiple slurs that emphasize the beat and bring clarity to the angularity of the line.

Figure 3.1. Alexander Glazunov, Concerto in E-flat Major for Alto Saxophone and String Orchestra, Op. 109, Leduc editon measure 108 - 111: Placement of phrase markings.

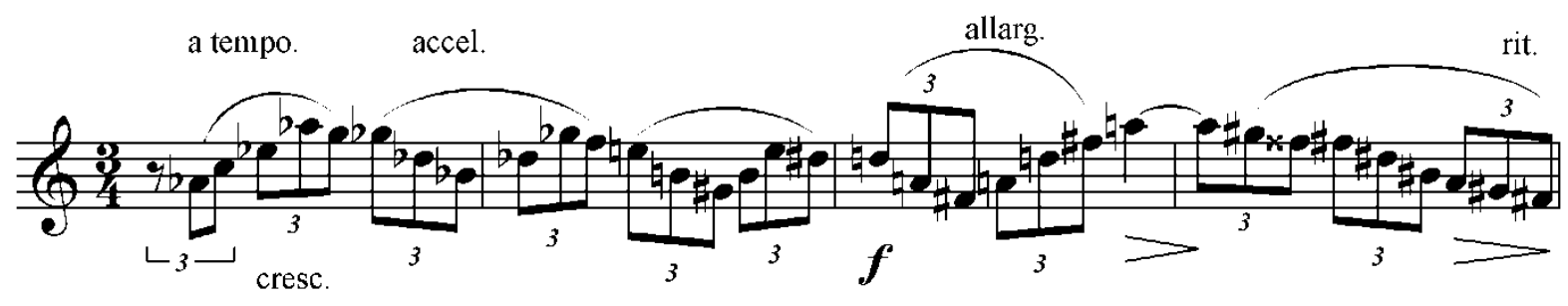

The Bärenreiter edition (Figure 3.2) is simpler in this regard, making clear the large overall phrase and suggesting a more sostenuto, lyrical approach.

\footnotetext{
${ }^{32}$ Two saxophone solo parts are included with the Bärenreiter edition: the part originally published by Leduc and the new edition of the solo part. For the purposes of the comparative analysis, the author is referring to the latter as the Bärenreiter edition
} 
Figure 3.2. Alexander Glazunov, Concerto in E-flat Major for Alto Saxophone and String Orchestra, Op. 109, Bärenreiter edition measure 108 - 111: Placement of phrase markings.



The Leduc Edition indicates slurs and not phrases where in places an understanding of the phrase is to be assumed. However, the Bärenreiter edition indicates the overall phrases while assuming that the performer will tongue certain note to insure that they respond clearly.

By the second half of the twentieth century many composers began to demand a more specific and detailed indication of musical elements such as articulation, dynamics, fingering, breathing, and, in the case of composers such as Karlheinz Stockhausen and George Crumb, choreography and position on stage. The most significant piece in the saxophone repertoire which incorporates this type of musical notation is Edison Denisov's Sonate for Alto Saxophone and Piano of 1970. Denisov's work includes a highly specific notation that indicates melodic lines which accelerate or decelerate; effects such as flutter-tonguing; a wide range of textural sounds; and frequent often very abrupt contrasts in dynamics and articulation. Specific fingerings and voicing adjustments are indicated in the music to guide the performer in executing multiphonics and quarter-tones. In an attempt to best communicate the Romantic style of Glazunov’s work, Bärenreiter has applied the same modern practice of notation through specific articulation markings. Since Bärenreiter has included specific articulation markings, the author has listed the different indications for the specific articulations, the proper attacks and releases, and the character of the articulations in Table 3.1. 
Table 3.1. Bärenreiter articulations: attacks and releases

\begin{tabular}{|l|c|l|l|l|}
\hline Articulation & Notation & Attack Syllable & Release & Characteristic \\
\hline Legato/Tenuto & $\mathbf{F}$ & Taa or Daa & $\begin{array}{l}\text { Long air } \\
\text { release/articulation } \\
\text { of next note }\end{array}$ & $\begin{array}{l}\text { Connected } \\
\text { articulation }\end{array}$ \\
\hline Staccato & $\mathbf{F}$ & Ta & $\begin{array}{l}\text { Short Air Release } \\
\text { or tongue cut-off }\end{array}$ & $\begin{array}{l}\text { Short detached } \\
\text { articulation }\end{array}$ \\
\hline Detached Legato & $\mathbf{F}$ & Taa or Daa & Air release & $\begin{array}{l}\text { Detached full } \\
\text { value articulation }\end{array}$ \\
\hline Accent & $\mathbf{F}$ & Strong Ta or Ka & $\begin{array}{l}\text { Long air } \\
\text { release/articulation } \\
\text { of next note }\end{array}$ & $\begin{array}{l}\text { full value } \\
\text { articulation }\end{array}$ \\
\hline Accented Legato & $\mathbf{F}$ & $\begin{array}{l}\text { Strong Taa or } \\
\text { Kaa }\end{array}$ & $\begin{array}{l}\text { Long air } \\
\text { release/articulation } \\
\text { of next note }\end{array}$ & $\begin{array}{l}\text { Connected } \\
\text { articulation }\end{array}$ \\
\hline
\end{tabular}

Detailed information on the proper execution of the saxophone articulations listed in Table 3.1 is published in HELLO! Mr. SAX by Jean-Marie Londeix. ${ }^{33}$ In addition to articulation markings, Bärenreiter has also included specific fingerings and breath marks.

The Concerto was written in 1934 and published by Leduc in 1936, before the modern practice of such musical indication came into common use. As a result, much of the detailed musical indications in the Bärenreiter edition are not present in the Leduc edition.

When comparing these two editions, the cadenza is of particular interest as Bärenreiter has included substantial new material in this section of the work. In the Leduc edition, only one cadenza is present. However, the Bärenreiter edition contains three different cadenzas:

Glazunov's standard cadenza as presented in the Leduc edition; a much shorter cadenza which appears to be a truncated version of the standard cadenza; and a third and very different cadenza composed by Sigurd Rascher.

\footnotetext{
${ }^{33}$ Jean-Marie Londeix, HELLO! Mr. Sax (Paris: Editions Musicales Alphonse Leduc), 86.
} 
Although the Concerto is in one movement, it comprises three major sections. Sigurd Rascher explains it in the following manner: “...though the work is in one movement, it possesses three independent parts, following the traditional concerto model.” ${ }^{34}$ These parts are divided as follows: Section one is the first sixty-six measures, Section Two is measures 67 164, and Section Three is measures 165 to the end of the work, measure 329.

\section{The Saxophone Solo Part: Section One}

The saxophone enters at measure 11, measures 11 - 22 (Figure 3.3) show identical dynamic markings with exception of measure 13; the Bärenreiter edition shows a decrescendo not present in the Leduc edition.

The most significant differences between the Leduc edition and the Bärenreiter edition become apparent as the phrasing and articulations differ substantially between the two editions. The notable differences are the placement of the slurs. In the Leduc edition, phrases are broken into multiple slurs which aid in emphasizing the harmonic changes.

Legato articulations in the Bärenreiter edition are notated in measure 11, the end of measure 14, and measure 21. Bärenreiter also includes detached legato indications in measures 13, 14, 19, and 20. These detailed articulation indications are not present in Leduc's edition. In addition to the specific articulations, the Bärenreiter edition includes breath marks in measures 15, 17, and 22. These markings allow an adequate supply of air to the performer, while maintaining continuous sense of musical momentum.

\footnotetext{
${ }^{34}$ Alexander Glazunov and Erland von Koch, Music Minus One Alto Saxophone, Glazunov/von Koch: Concertos in E-Flat Major (Elmsford, NY: Music Minus One, 2000), 5.
} 
Figure 3.3. Alexander Glazunov, Concerto in E-flat Major for Alto Saxophone and String Orchestra, Op. 109, measures 11 - 26: Articulations and placement of phrase markings.
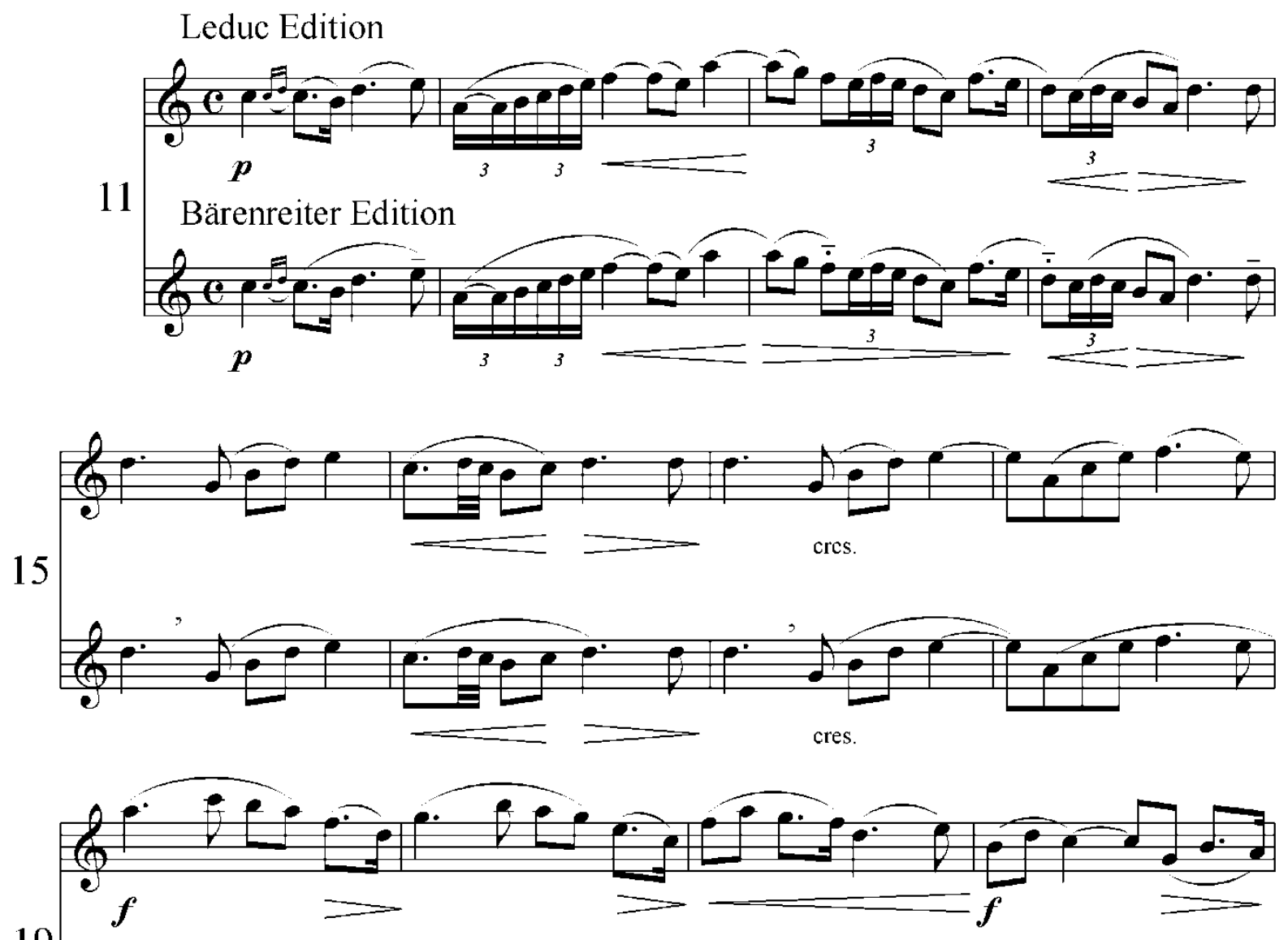

19
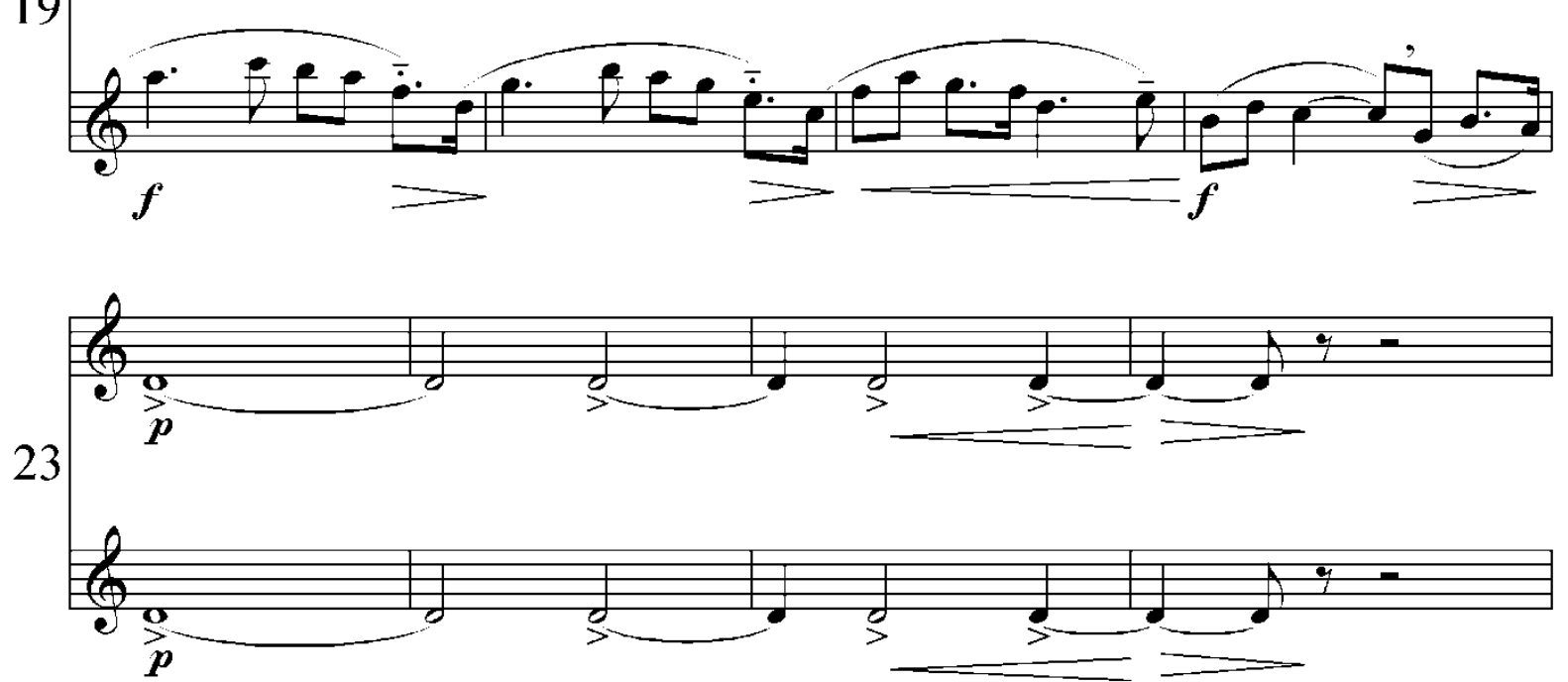
In contrast to Leduc’s harmonic approach encouraged by multiple small groups of slurs, Bärenreiter presents a horizontal approach with a broader, songlike character. These differences in the placement of the slurs are indicated in Table 3.2.

Table 3.2: Differences in slur placement

\begin{tabular}{|c|c|c|}
\hline Measure Numbers & Leduc Edition & Bärenreiter edition \\
\hline 11 & Beats 1,2 , and 3 are tongued. & Beats 1 and 2 are tongued. \\
\hline 12 & Beats 1,2 , and 4 are tongued. & Beats 1 and 4 are tongued. \\
\hline 13 & Beats 2 and 4 are tongued. & Beats 1,2 , and 4 are tongued. \\
\hline 15 & Beats 1 , the " $\&$ " of 2 , and 4 are tongued. & Beats 1 and the "\&" of 2 are tongued. \\
\hline 16 & Beats 1,3 , and the " $\&$ " of 4 are tongued. & Beats 1 and the "\&" of 4 are tongued. \\
\hline 17 & Beats 1 , the " $\&$ " of 2 , and 4 are tongued. & Beats 1 and the "\&" of 2 are tongued. \\
\hline 18 & The "\&" of 1 and 3 are tongued. & The " $\&$ " of 1 is tongued. \\
\hline 19 & Beats 1 and 4 are tongued. & Beats 1 and 4 and the "a" of 4 are tongued. \\
\hline 20 & Beats 1 and 4 are tongued. & Beats 4and the "a" of 4 are tongued. \\
\hline 21 & Beats 1 and three are tongued. & All notes are slurred. \\
\hline
\end{tabular}

Measures 27 - 36 (Figure 3.4) represent the continuation of Section One; the two editions continue to differ in their phrasing and articulation markings. Here, Leduc indicates the slurs; the saxophonist's understanding of the phrase is assumed. However, Bärenreiter indicates the phrases while assuming that the player may articulate certain notes in order to effectively interpret the melodic line. Although both editions require the player to have a strong 
understanding of the piece, the new edition encourages longer lines and promotes greater phrase direction by the use of these articulations.

Figure 3.4. Alexander Glazunov, Concerto in E-flat Major for Alto Saxophone and String Orchestra, Op. 109, measures 27 - 36: Articulations and placement of phrase markings.

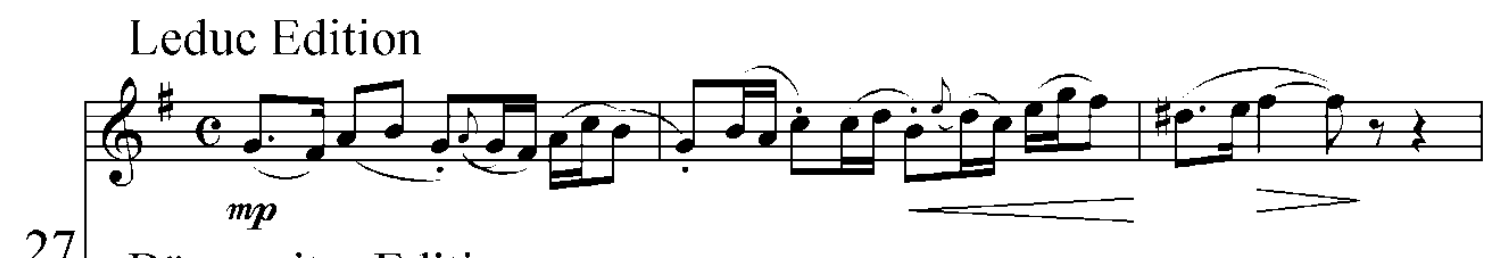

27
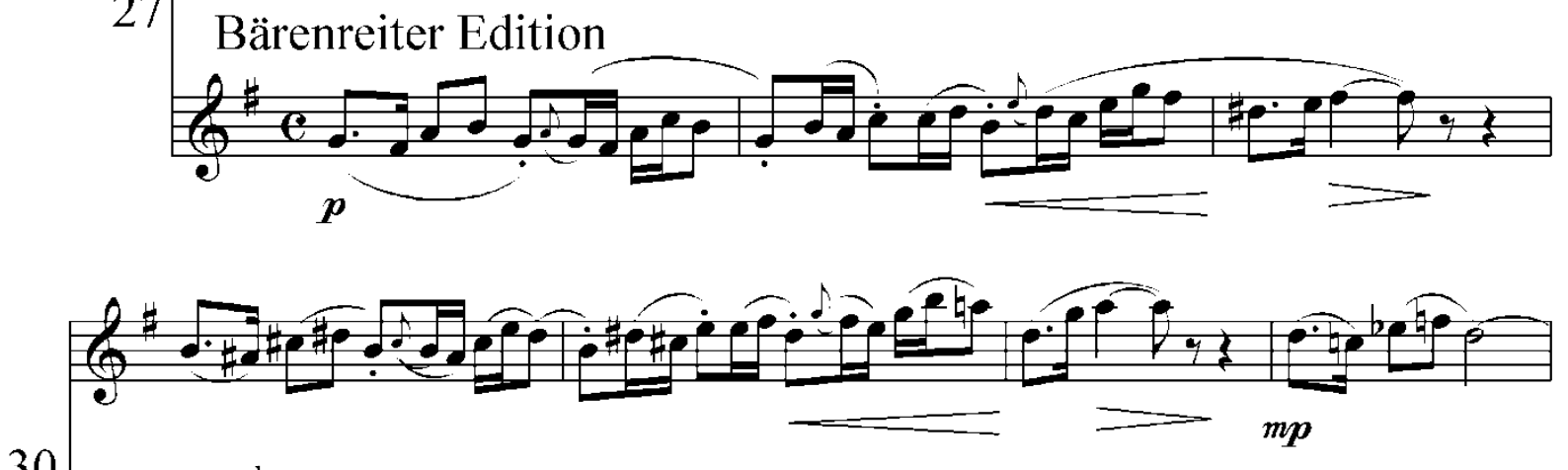

30


The dynamic markings in this section are virtually identical in both editions with the exception of the indication on the downbeat of measure 27. In the Bärenreiter edition, the dynamic level is marked piano and in the Leduc edition, mezzo piano. The Bärenreiter edition continues the same dynamic marking as the opening, while the Leduc edition highlights greater contrast. 
Also unique to the Bärenreiter edition are the specific fingerings ${ }^{35}$ in measures 30 and 31. The $\mathrm{C}$ - sharps are labeled " 5 "* or " 0 " and the $\mathrm{A}$ - sharps are labeled "sk" ${ }^{ \pm}$over them. This notation, which indicates specific fingerings to be used, is not present in the Leduc edition.

Further differences are present in measures 40 - 52 (Figure 3.5). The variation in phrase indication continues in this section with multiple slurs in the Leduc edition and a more sostenuto approach by Bärenreiter as in measures $11-21$ and 27 - 36. Indications of staccato attacks in measures 43, 47, 50, and 52, are present in the Leduc edition. However, more articulations are notated in Bärenreiter's edition: the same staccato markings are indicated as well as detached legato attacks in measures 43, 47 and 50, a legato attack in measure 51, and a staccato attack in measure 46. Other specific indications unique to the Bärenreiter edition are breath marks in measures 44, 48, and 50, and the “sk” fingering for A - sharp marking in measure 49.

\footnotetext{
${ }^{35}$ In order to clearly describe the specific fingerings indicated in the Bärenreiter edition, the author has used the key identification chart entitled "Chart of the Saxophone" on page 6 of HELLO! Mr. Sax by Jean-Marie Londeix.

*Fingering for this note: 8va-1-2-3-4-5-6-C\# (See "Chart of the Saxophone" in Londeix, HELLO! Mr. Sax,6)

${ }^{+}$Fingering for this note: no keys are depressed (open C sharp)

${ }^{ \pm}$Fingering for this note: 1- 2- Ta (See "Chart of the Saxophone" in Londeix, HELLO! Mr. Sax,6)
} 
Figure 3.5. Alexander Glazunov, Concerto in E-flat Major for Alto Saxophone and String Orchestra, Op. 109, measures 40 - 52: Articulations and placement of phrase markings.
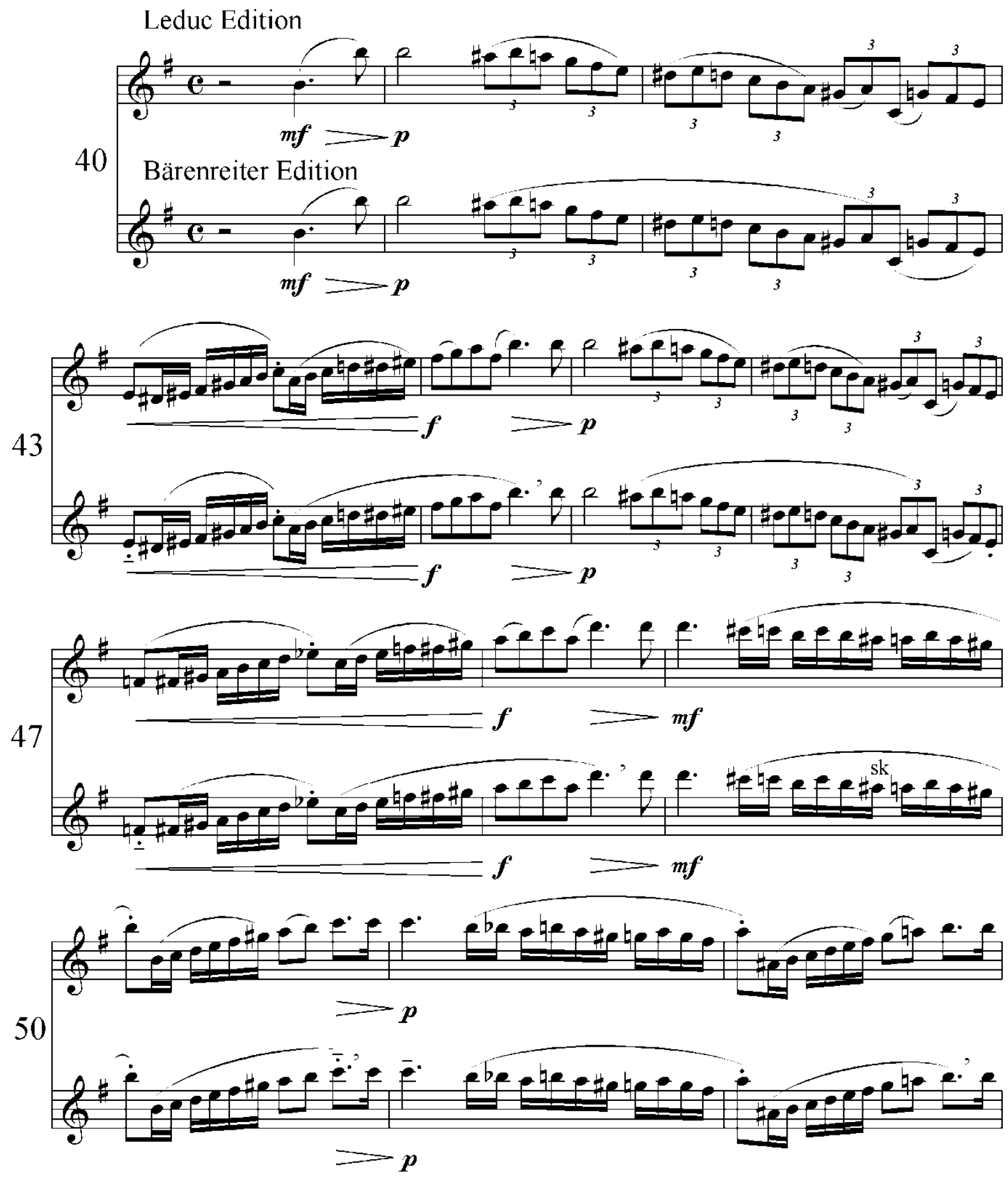

The breath marks in measures 44, 48, and 50 of the Bärenreiter edition occur after the first of three repeated notes; the last of the three notes is on the downbeat of the measure. As a 
result of this placement of the breath, the second of the three notes becomes the anacrusis for the next phrase. This is significant because many saxophonists have learned this work through study of the Leduc edition which does not specify where breaths should be taken. Consequently, it has become common practice among saxophonists to play this section by taking a breath after the third repeated note making it the last note of the preceding phrase. These two interpretations are quite different yet they are both effective presentations of the musical lines.

The section spanning from measure 53 - 66 is the final portion of Section One and is very similar in both editions. They are virtually identical with the exception of the phrasing in measures 59 - 61 (Figure 3.6).

Figure 3.6. Alexander Glazunov, Concerto in E-flat Major for Alto Saxophone and String Orchestra, Op. 109, measures 59-61: Articulations and placement of phrase markings.

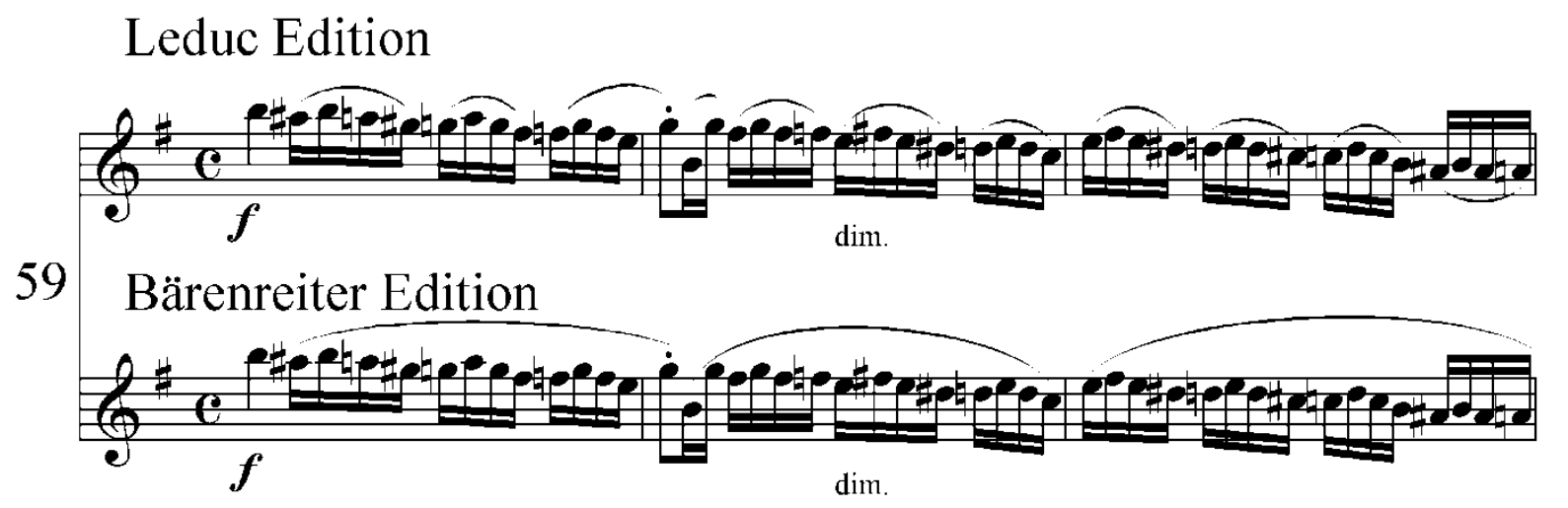

These differences in phrase markings between the two editions present Bärenreiter’s most significant changes to this section of the work. In the Leduc edition In the Leduc edition, the harmonic rhythm is brought out by a more frequent use of slurs. Bärenreiter seeks a more horizontal interpretation, where larger groups of notes are slurred, suggestive of a more sostenuto approach. Further differences in this section are more subtle; there are indications in the Bärenreiter edition that are not present in the Leduc edition. They are as follows: the staccato 
attacks in measures 54 and 56, the “sk” marking in measure 53, and breath marks which have been added in measures 57 and 58.

\section{The Saxophone Solo Part: Section Two}

The fourteen measure orchestral interlude beginning at measure 67 marks the beginning of the tranquillo second section. The first entrance of the saxophone in this section is at measure 81 (Figure 3.7).

The phrasing between the two editions is quite different. Leduc continues to break the phrases into multiple slurs, contrasted to Bärenreiter’s broader, sostenuto approach. Specific markings for the attacks and releases of notes differ between the two editions. In the Leduc edition, the half note in measure 84 is marked with an accent; it is not accented in Bärenreiter's edition. The detached legato notes in measures 87, 91, 94, and 101 of Bärenreiter's edition are not present in Leduc's; neither are the legato markings in measures 86 and 98.

In this section, Bärenreiter continues to be more specific in its indications of certain musical elements. This is apparent in measure 83 as the D - flat on beat three is marked with the number 5, indicating a specific fingering. Also, measures 88, 91, 96, 98, and 99 contain breath marks. None of these markings are present in the Leduc edition. 
Figure 3.7. Alexander Glazunov, Concerto in E-flat Major for Alto Saxophone and String Orchestra, Op. 109, measures 81 - 103: Articulations and placement of phrase markings.

Leduc Edition

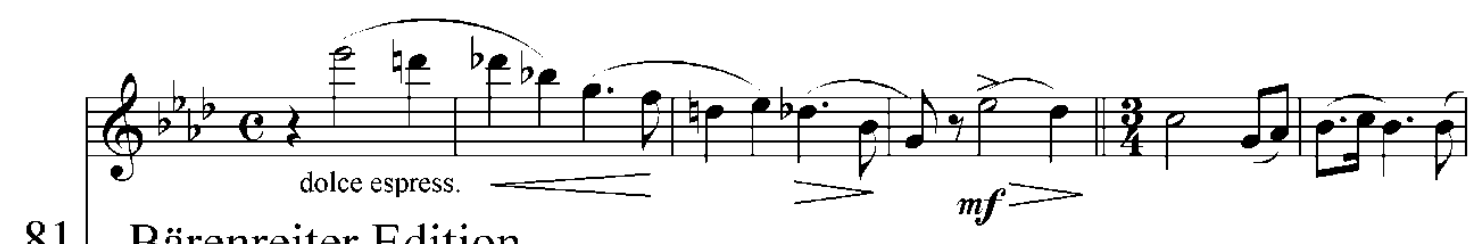

81
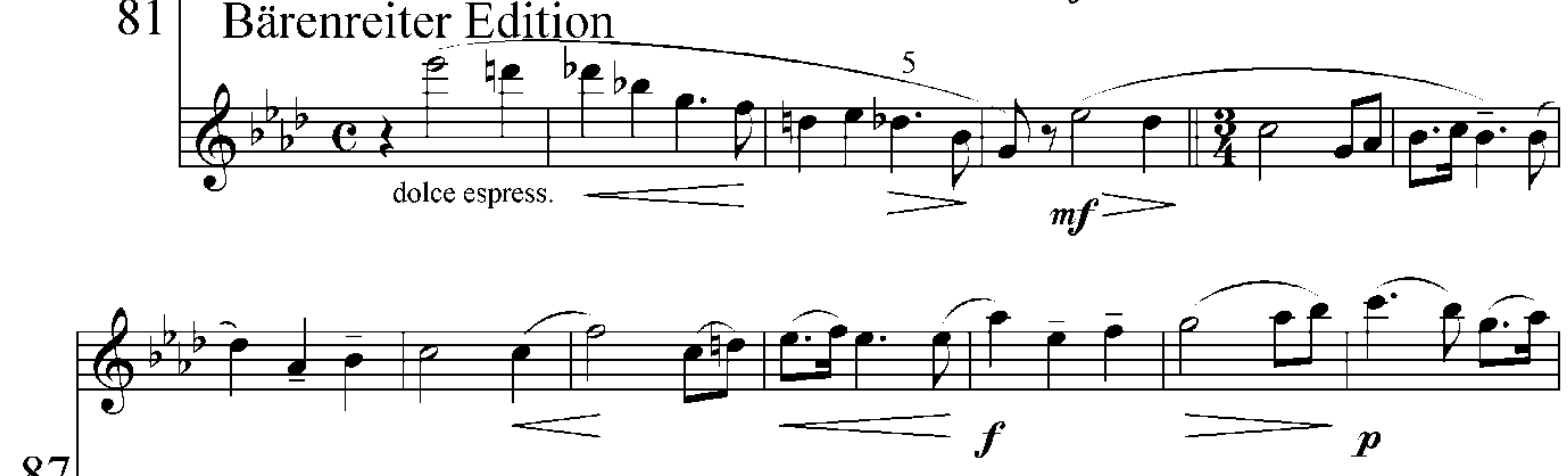

87
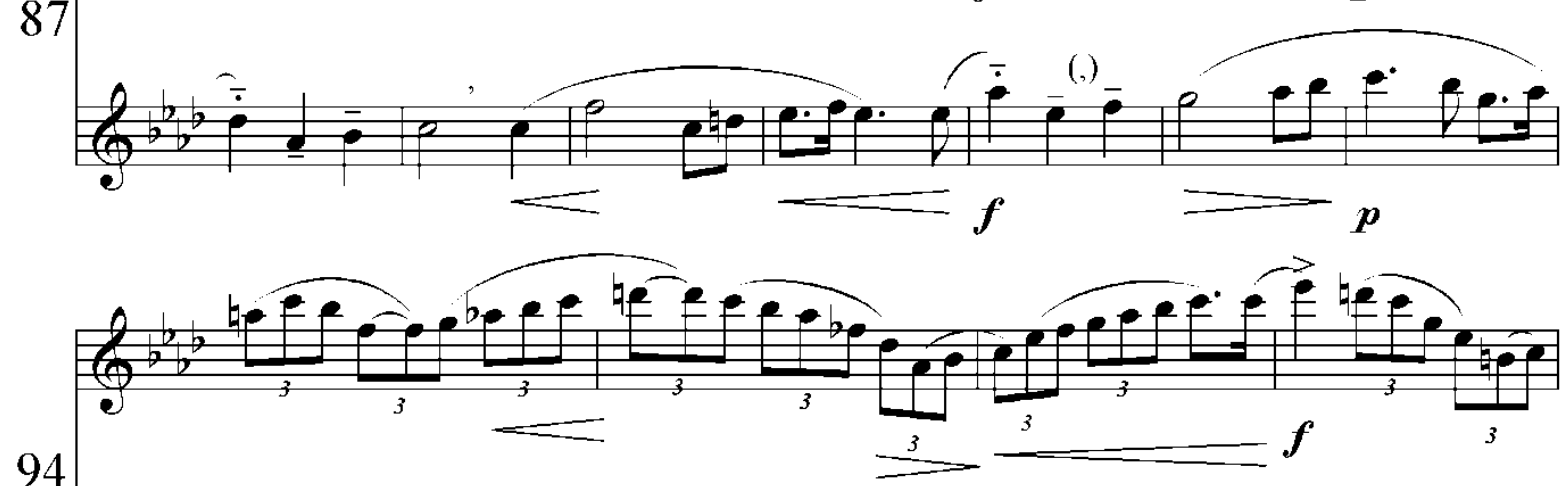

94
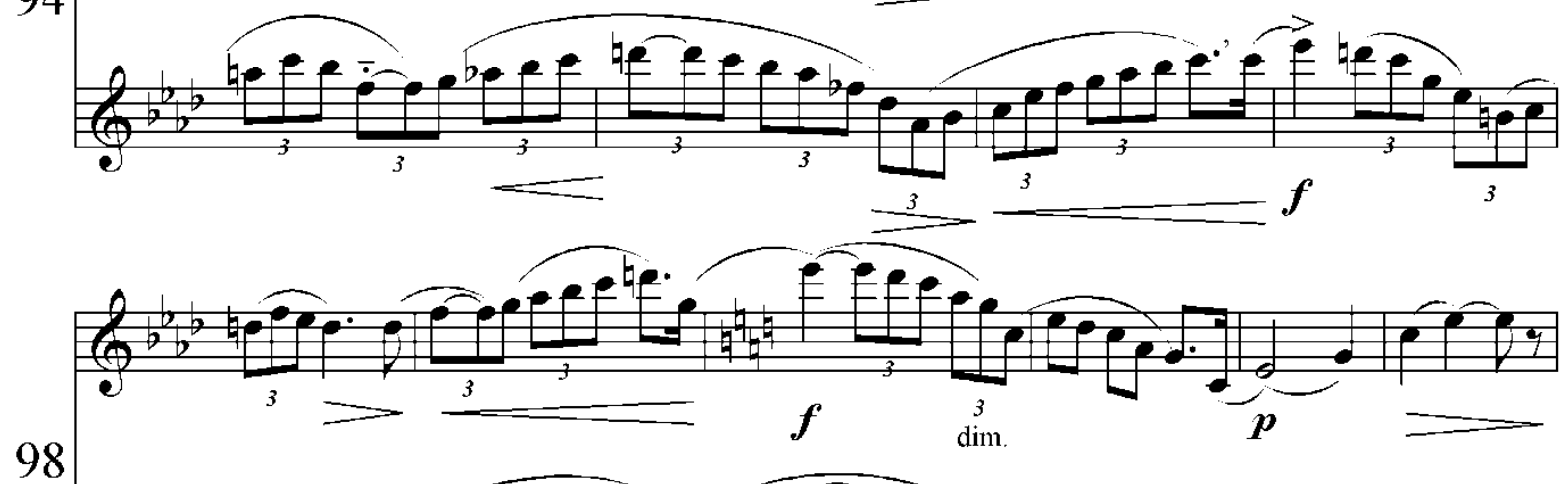

98

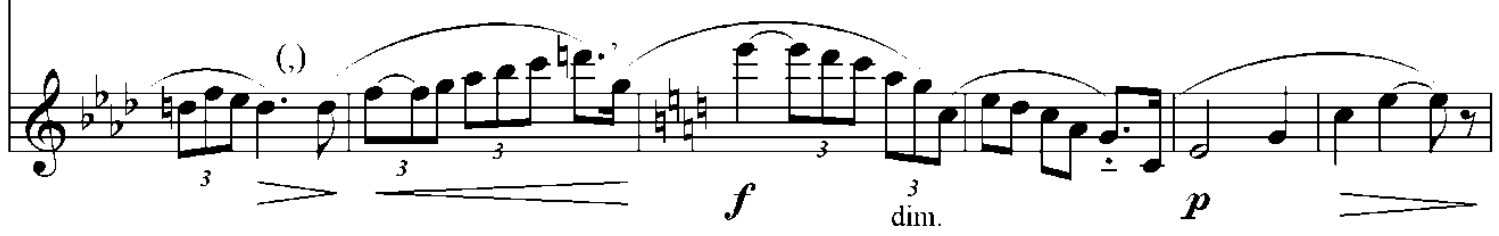


The differences between the two editions of this work are very significant in measures 104 - 119. Even though measures 116 - 119 are virtually identical, with the exception of a diminuendo indicated in the Bärenreiter edition, measures 104 - 115 show two very different presentations of the phrasing (Figure 3.8). 
Figure 3.8. Alexander Glazunov, Concerto in E-flat Major for Alto Saxophone and String Orchestra, Op. 109, measures 104 - 119: Articulations and placement of phrase markings.

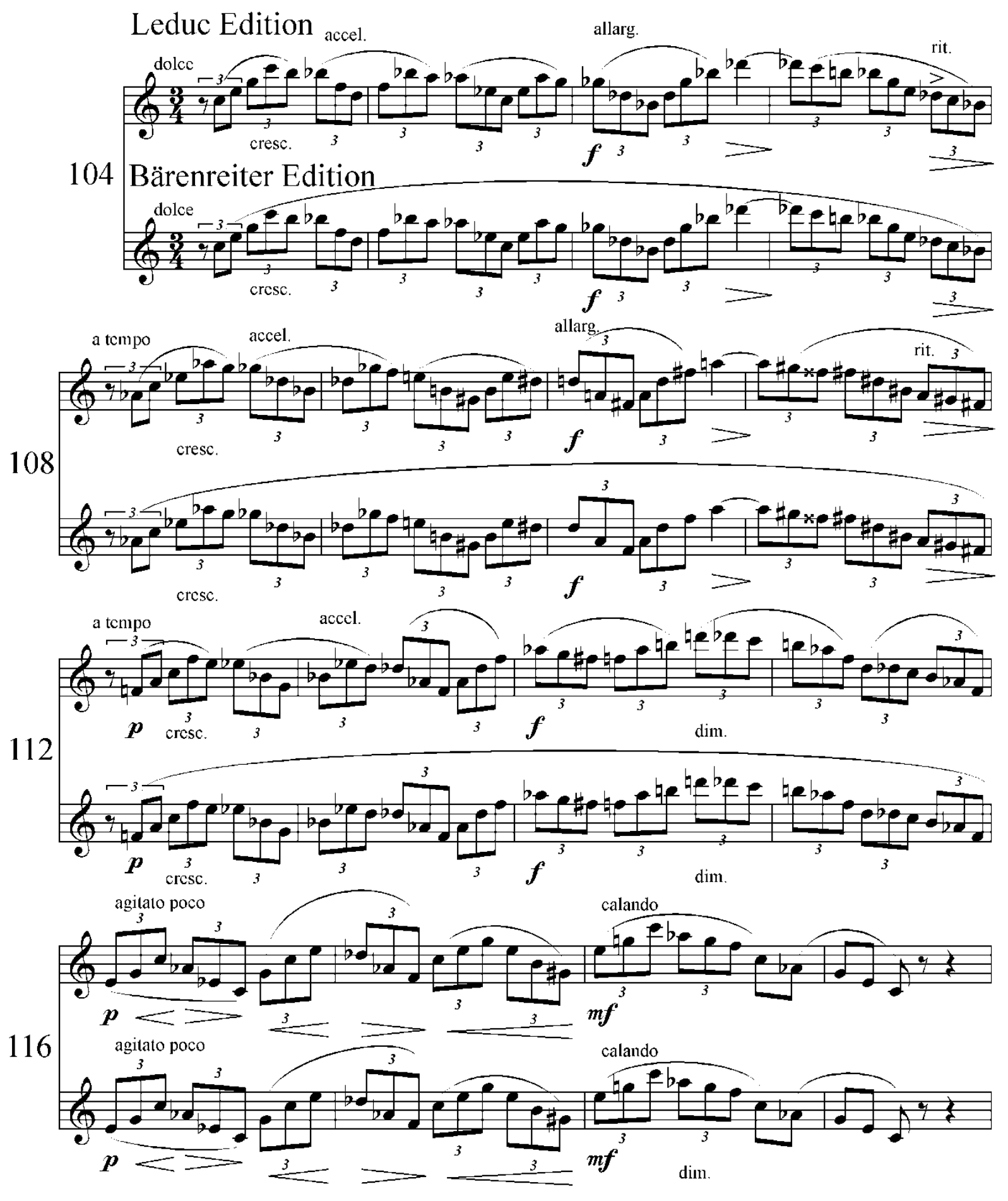

In the Leduc edition, the phrases are broken into several slurs in order to clearly define the harmonic changes and the melodic sequence. However, Bärenreiter has provided a broad 
horizontal approach to the phrase structure which implies a broad, singing character. In this section, Leduc has included accelerando, allargando, and ritardando indications which guide the saxophonist through the melodic line. These are not present in the Bärenreiter edition, and as a result, adjustments in tempo are left to the discression of the performer.

After a three measure orchestral interlude in measures 120 - 122, the saxophone enters in measure 123. Measure 120 marks the beginning of the next section (Figure 3.9) of Section Two which ends at measure 141. In regard to indications of dynamics, the two editions are identical. However, the differences in phrasing are quite apparent: Leduc continues with melodic lines that are sectionalized by multiple slurs and Bärenreiter continues with the a more songlike presentation. Discrepancies in articulation are present in the two editions: the accents in measures 128 and 132 of the Leduc Edition are not notated in the Bärenreiter edition. Furthermore, the detached legato indications in measures 124, 128, and 132 of Bärenreiter's edition are not present in that by Leduc. 
Figure 3.9. Alexander Glazunov, Concerto in E-flat Major for Alto Saxophone and String Orchestra, Op. 109, measures 123 - 141: Articulations and placement of phrase markings.

Leduc Edition

123

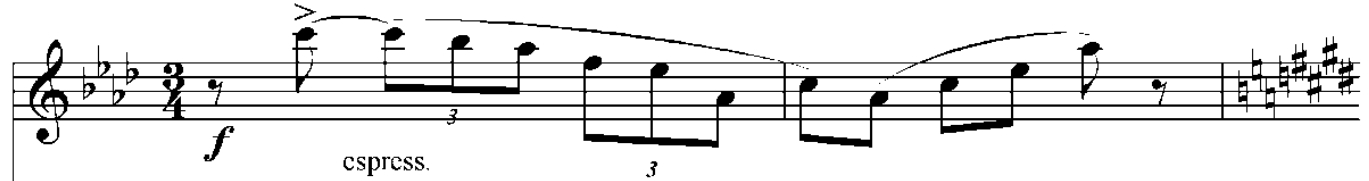

Bärenreiter Edition dim

The fifth part of Section Two, measure 142 - 154, begins with a three-measure interlude by the orchestra; the saxophone enters at measure 145 (Figure 3.10).

Figure 3.10. Alexander Glazunov, Concerto in E-flat Major for Alto Saxophone and String Orchestra, Op. 109, measures 145 - 154: Articulations and placement of phrase markings.

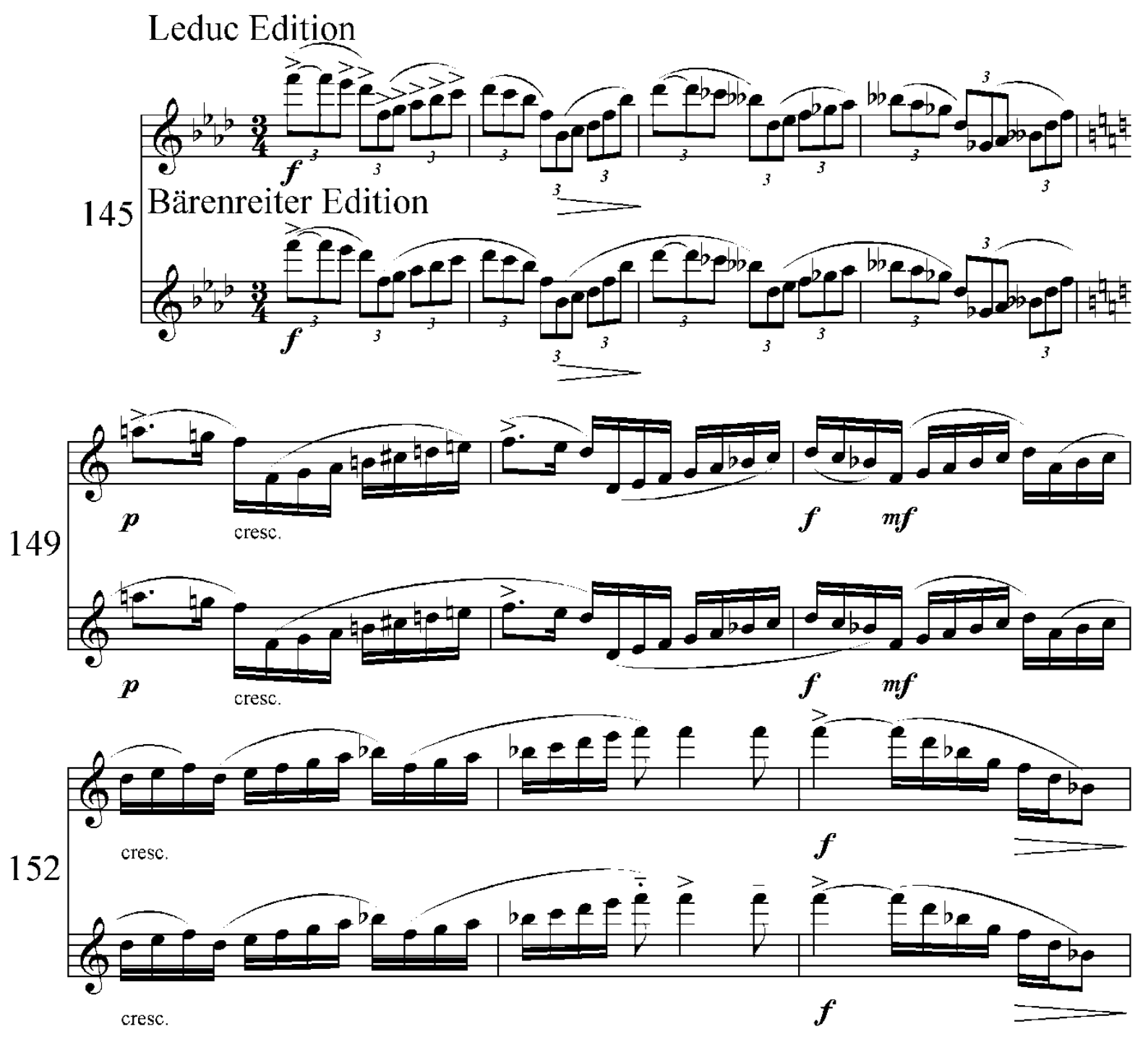

As has been the case with the preceding sections of this work, the most significant differences between the two editions pertain to phrasing and slur placement. There are some important differences in articulation in measures 145 and 153: the accent markings present in measure 145 
of the Leduc edition are not indicated in the Bärenreiter edition. Further differences are in measure 153, in Bärenreiter’s edition specific articulations (detached legato, accent, and legato) are indicated over the notes on beats two and three. These are not present in the Leduc edition. Measures 155 - 163 are a transition into the cadenza. Here the two editions of the Concerto differ in only two minor places: measures 155 - 156 (Figure 3.11) and 159 - 160 (Figure 3.12).

Figure 3.11. Alexander Glazunov, Concerto in E-flat Major for Alto Saxophone and String Orchestra, Op. 109, measures 155 - 156: Articulations and placement of phrase markings.

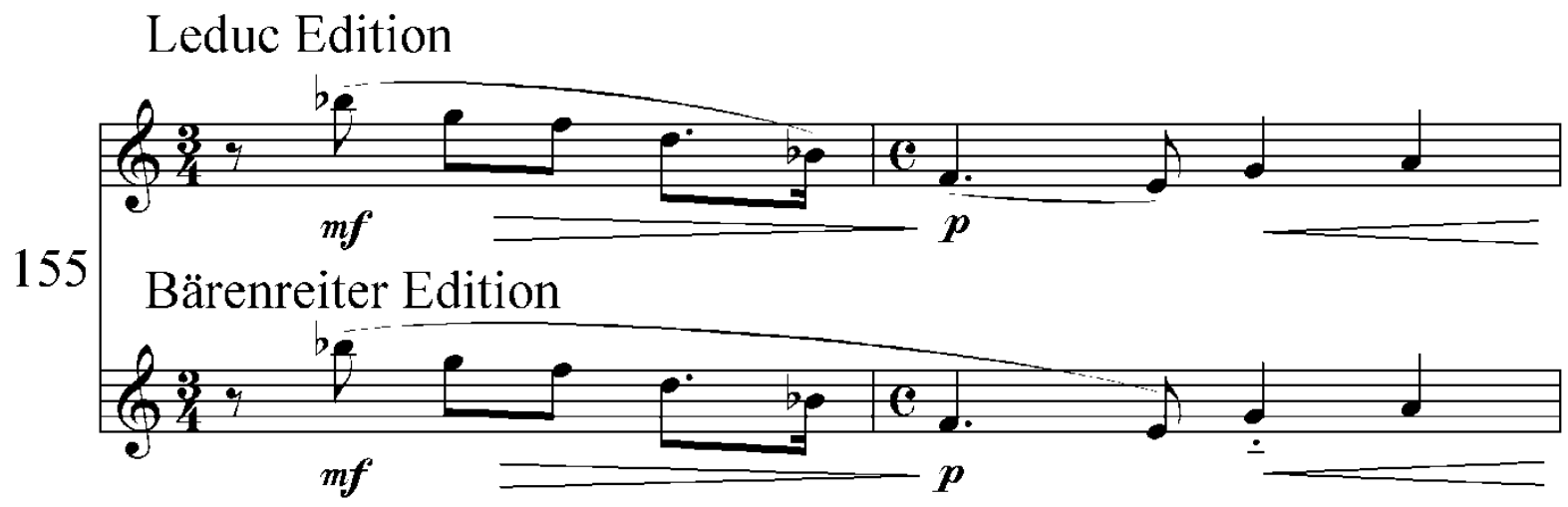

The phrasing in these two measures differs slightly between the editions. In the Bärenreiter edition, the slur beginning in measure 155 carries through beat two of measure 156, but in the Leduc edition, the slur beginning in measure 155 carries through beat four of the measure with the downbeat of measure 156 articulated. In addition, Bärenreiter has indicated that the quarter note on beat three of measure 156 is to be played with a detached legato attack.

The differences in measures 159 - 160 are minimal (Figure 3.12). In the Bärenreiter edition, the A - flat whole note in measure 159 is tied to the $G$ - sharp on the downbeat of measure 160; these notes are not tied in the Leduc edition. The Leduc edition also places a decrescendo under measure 159. 
Figure 3.12. Alexander Glazunov, Concerto in E-flat Major for Alto Saxophone and String Orchestra, Op. 109, measures 159 - 160: Articulations and placement of phrase markings.

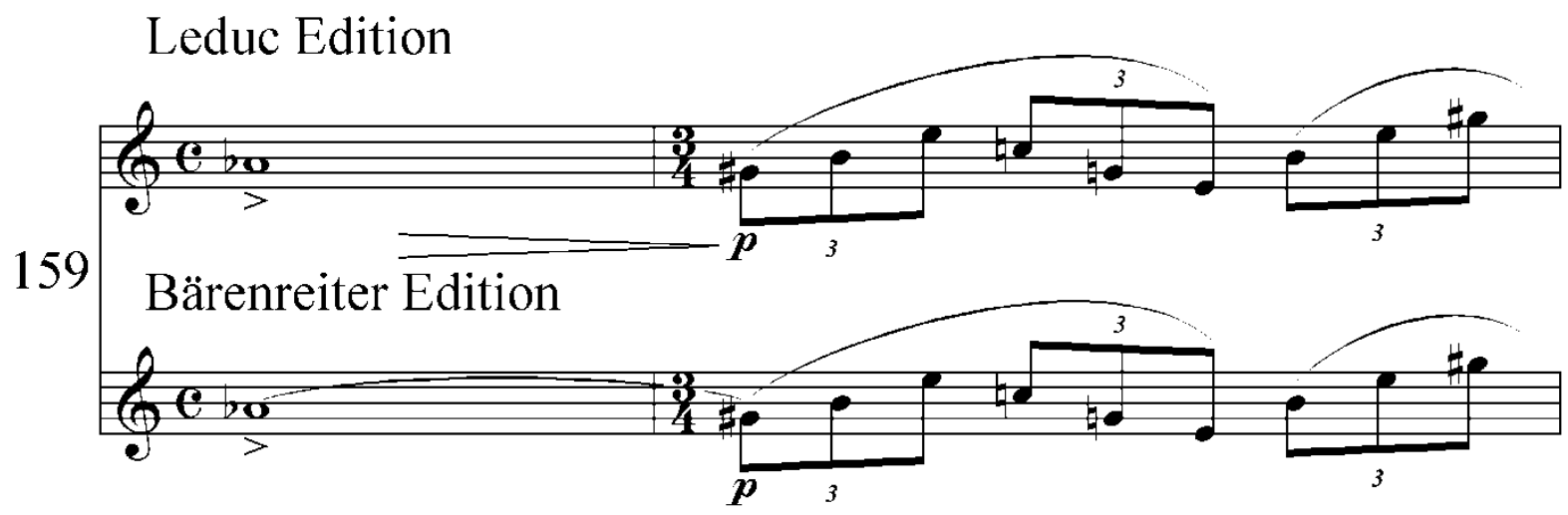

The seventh part (Figure 3.13) of Section Two, measures 163 - 164, is the cadenza and contains some of the most significant differences between the two editions of this work. ${ }^{36}$ This cadenza is also present in the Bärenreiter edition as the second of three possible cadenzas; it is identical in both editions. This first cadenza (Figure 3.14) presented by Bärenreiter is a truncated version of the Leduc edition cadenza.

\footnotetext{
${ }^{36}$ Though the cadenzas illustrated in Figures 13 and 14 contain several measures, all of the material beginning in measure 164 is considered to be one measure.
} 
Figure 3.13. Alexander Glazunov, Concerto in E-flat Major for Alto Saxophone and String Orchestra, Op. 109, measures 163 - 164: The cadenza presented in the Leduc edition and the second cadenza presented in the Bärenreiter edition.
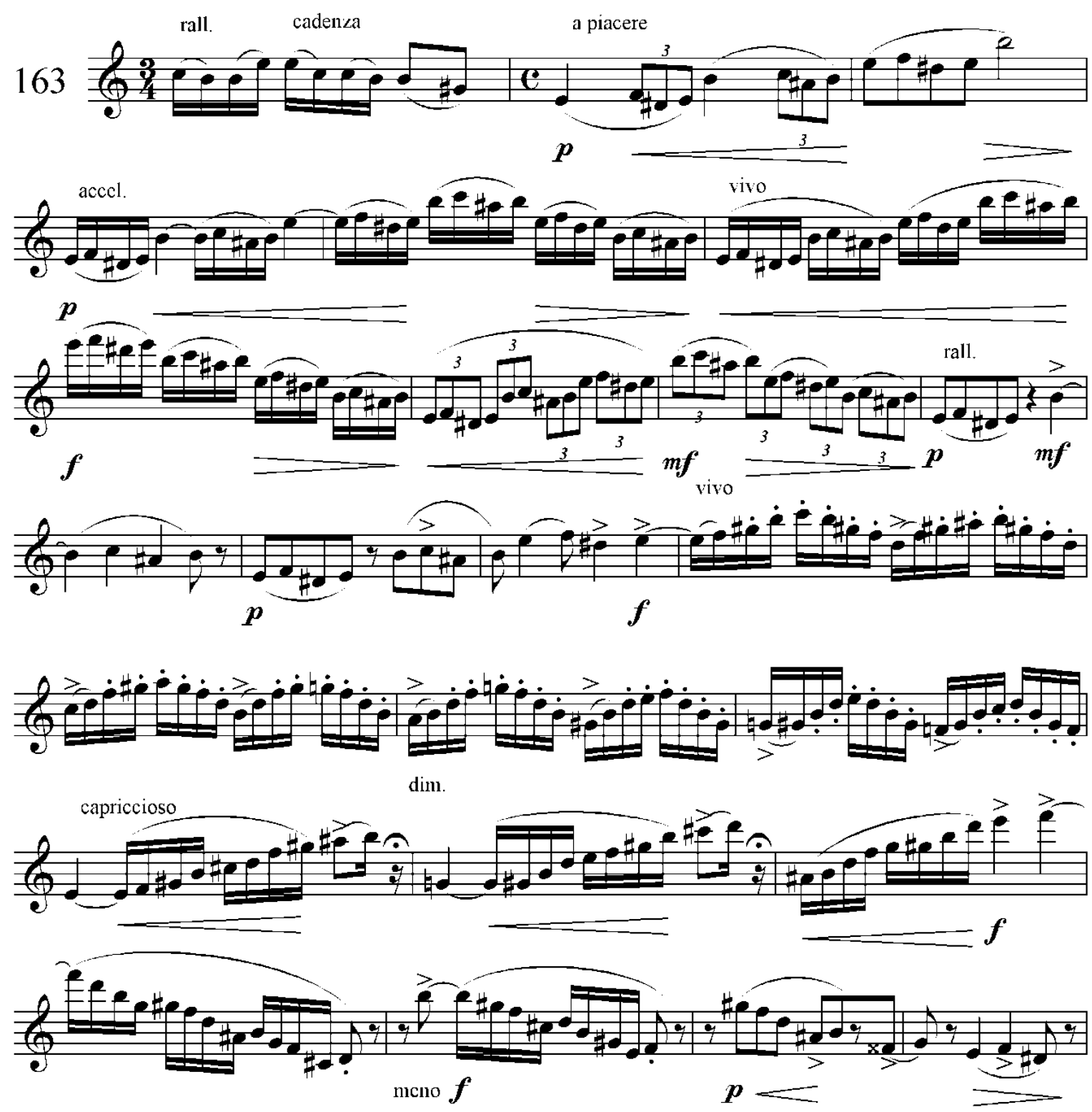

There is one slight difference between the first and the second cadenza in regard to phrasing. In the second cadenza (Figure 3.13), the slur beginning on beat three of measure 163 only spans two eighth notes; the downbeat of measure 164 is articulated. However, the same phrase in the first cadenza (Figure 3.14) is slightly diferent. The slur beginning on beat three of measure 163 is carried over to beat one of measure 164 . 
Figure 3.14. Alexander Glazunov, Concerto in E-flat Major for Alto Saxophone and String Orchestra, Op. 109, measures 163 - 164: The first cadenza presented in the Bärenreiter edition.

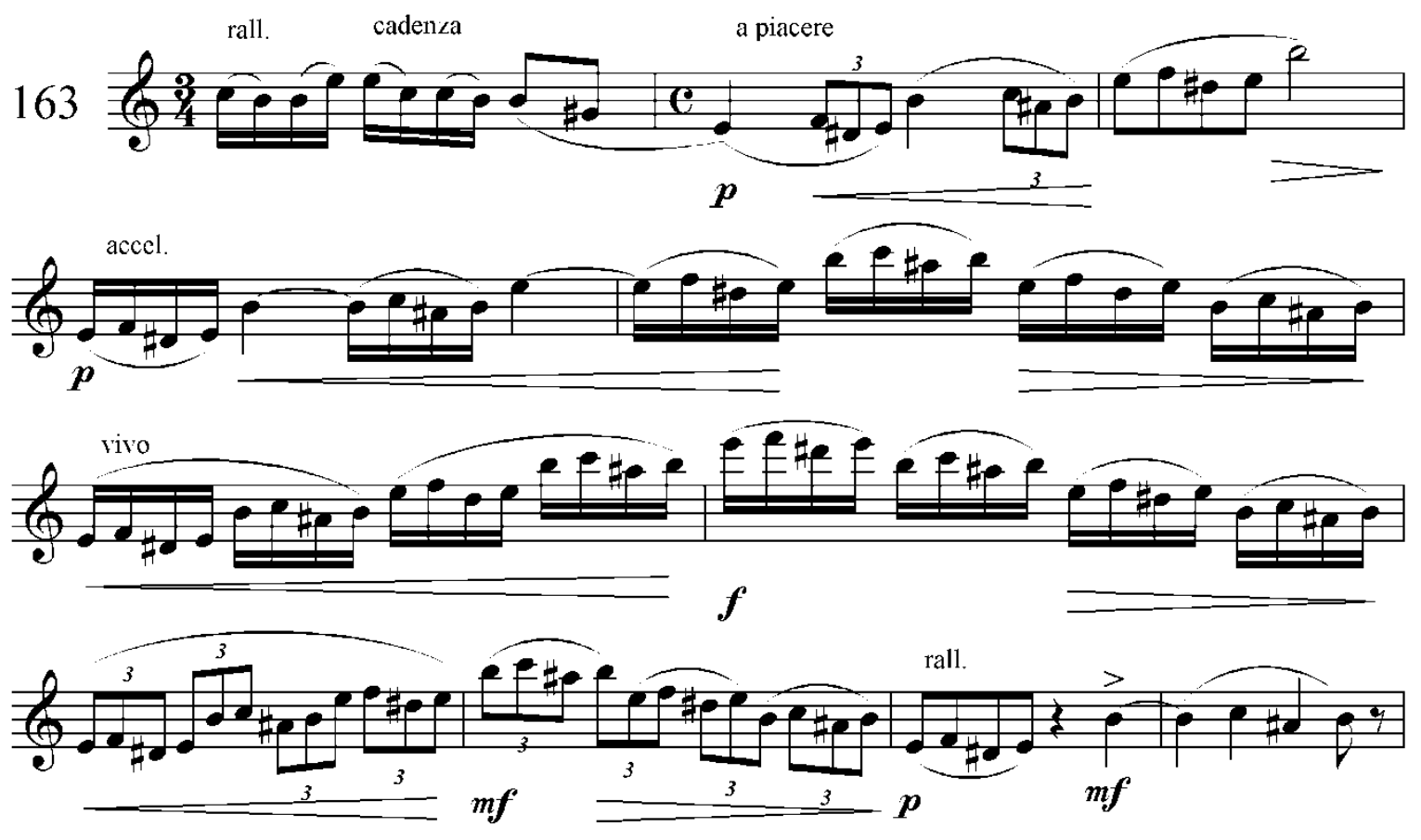

The third cadenza (Figure 3.15) in the Bärenreiter edition is completely different than the

first two. Cadenzas one and two were composed by Glazunov, but the third is by Sigurd

Rascher. Rascher recalls playing his cadenza for Glazunov: “... [I] played my own for him, he

listened to it a few times and meant it fit rather well, I should play it. [sic]”37

${ }^{37}$ Alexander Glazunov, Concerto In E-Flat Major for Alto Saxophone and String Orchestra (Kassel, Germany: Bärenreiter, 2010), XIV. 
Figure 3.15. Alexander Glazunov, Concerto in E-flat Major for Alto Saxophone and String Orchestra, Op. 109, measures 163 - 164: The third cadenza in the Bärenreiter edition.
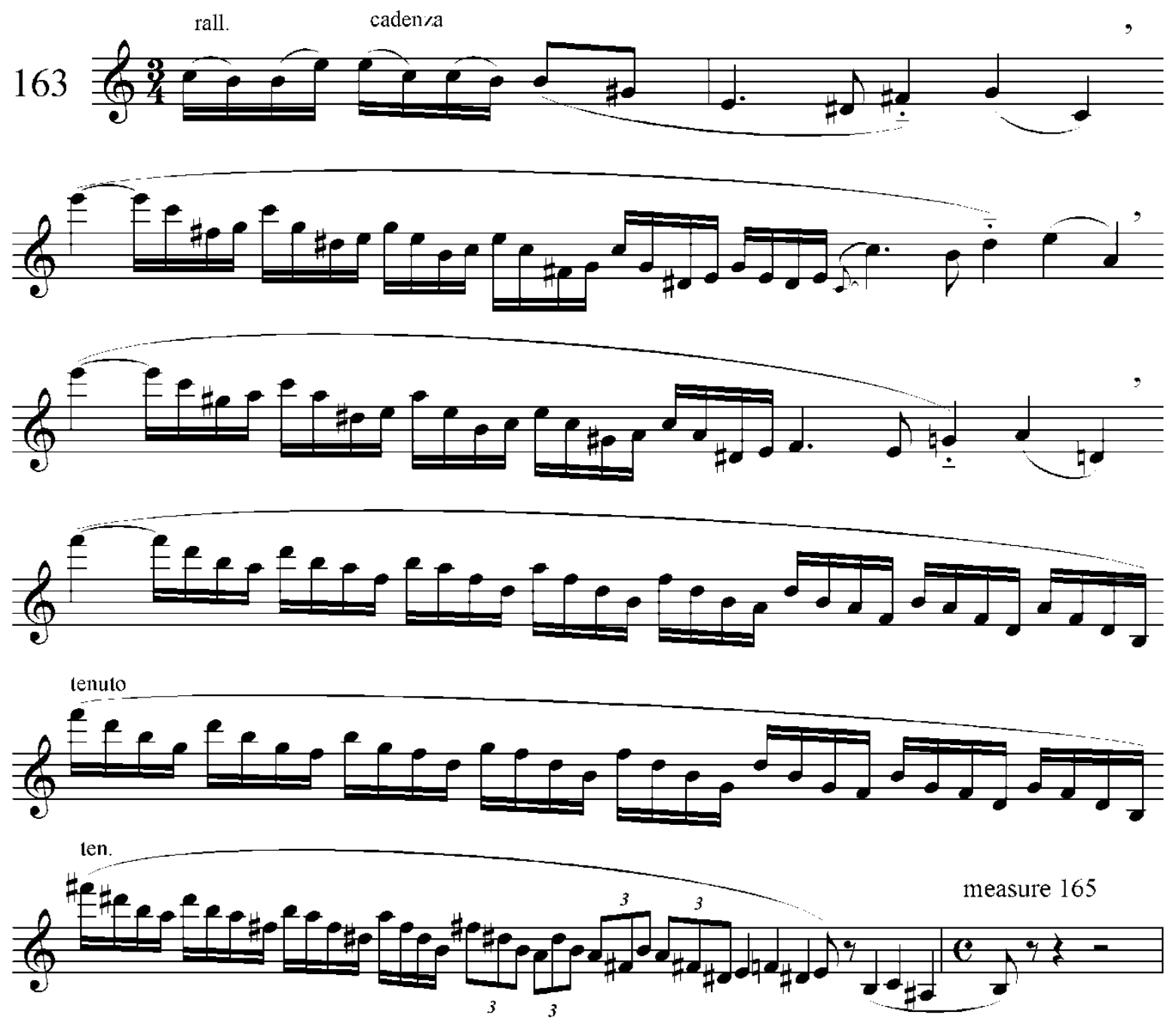

The Saxophone Solo Part: Section Three

Section Three begins at measure 165 (rehearsal number 22). Measures 165 - 178, which begins with a four-measure orchestral interlude, prepares the saxophone’s entrance in measure 169 with staccato eighth notes in octaves. Measures 165 - 175 are identical in both editions. However, in the last three measures of this section (Figure 3.16) the melodic content differs. This variance in the melodic material is a result of revisions Glazunov made in the two years 
between the initial composition of the Concerto (1934) and its publication (1936). Rascher discusses these changes: "In the three measures before rehearsal number 24 [measures 176 178] in the manuscript are no eighth-rests, but octaves, just as in the previous measures.”38

Figure 3.16. Alexander Glazunov, Concerto in E-flat Major for Alto Saxophone and String Orchestra, Op. 109, measures 176 - 178: Variation in melodic content.

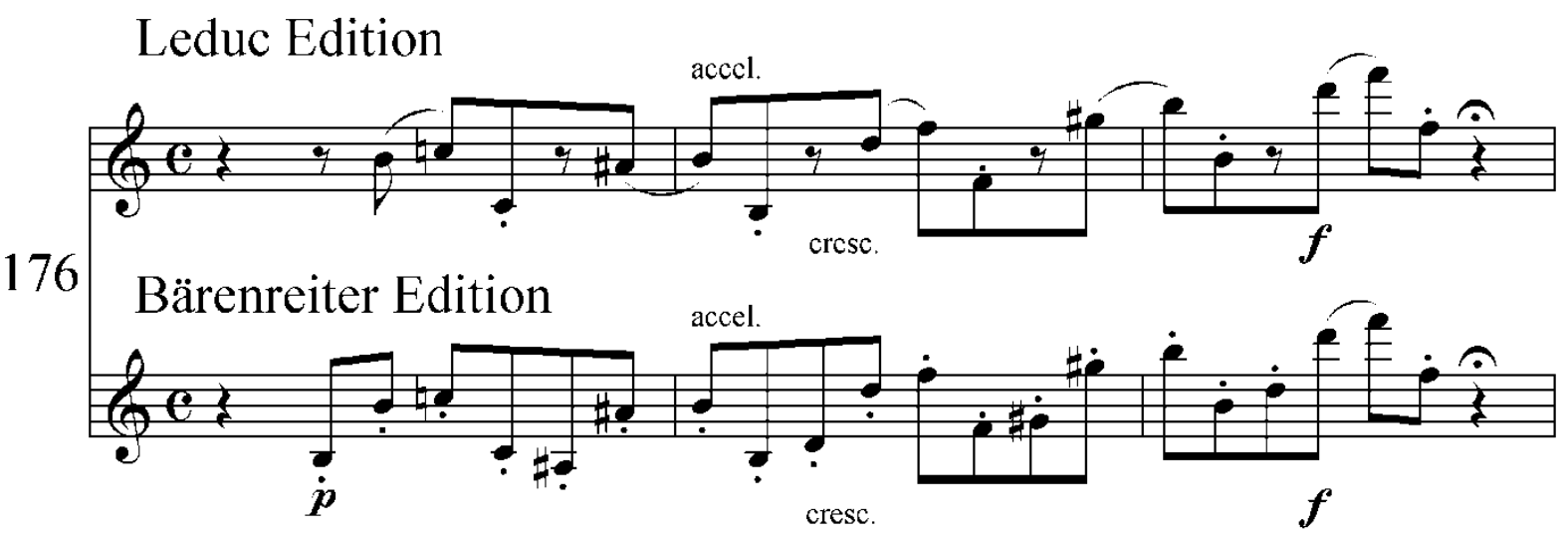

The next part of Section Three, measures 179 - 192 (Figure 3.17 and Appendix), contains discrepancies in the placement and length of slurs. In measure 180 of the Leduc edition, a slur begins on the last eighth note of beat three and extends through the quarter note on beat one of measure 181. In the Bärenreiter edition beat four of measure 180 is tongued, as are the last eighth note of beat four and the downbeat of measure 181. A slur begins on beat four of measure 181 in both editions, but the Bärenreiter in edition it carries over through the quarter note on beat one of measure 182; this pitch is tongued in Leduc's edition. The last eighth note of beat four of measure 182 is tongued in both editions, but in the Leduc edition it is the beginning of a slur that carries over through the second eighth note of measure 183, while in the Bärenreiter edition beat one of measure 183 is tongued and slurred to the second eight note of the beat. The last eighth

\footnotetext{
${ }^{38}$ Sigurd M. Rascher, “Alexander Glazunov: Concerto pour Saxophone avec l’orchestre de cordes.” Saxophone Symposium Volume XIII No.2 (Spring 1988): 17
} 
note of measure 183 is tongued in both editions but in the Leduc edition it is the beginning of a series of slurred notes which continues through the second eighth note of measure 184. In measure 184 of Leduc's edition beats two and three are tongued; In the Bärenreiter edition beats one and two are tongued. The dotted quarter note on beat one of measure 187 and the last eighth note of beat three are tongued in the Leduc edition. Bärenreiter indicates that the downbeat of this measure is under a slur which begins on beat four of measure 186; the quarter note and eighth note in beat three are tongued. Further differences in slur placement are present in measure 188. In the Leduc edition beat two and the last eighth note of beat three are tongued; beat two of the Bärenreiter edition is the beginning of a slur that carries through the downbeat of measure 189. 
Figure 3.17. Alexander Glazunov, Concerto in E-flat Major for Alto Saxophone and String Orchestra, Op. 109, measures 179 - 189: Articulations and placement of phrase markings.


183
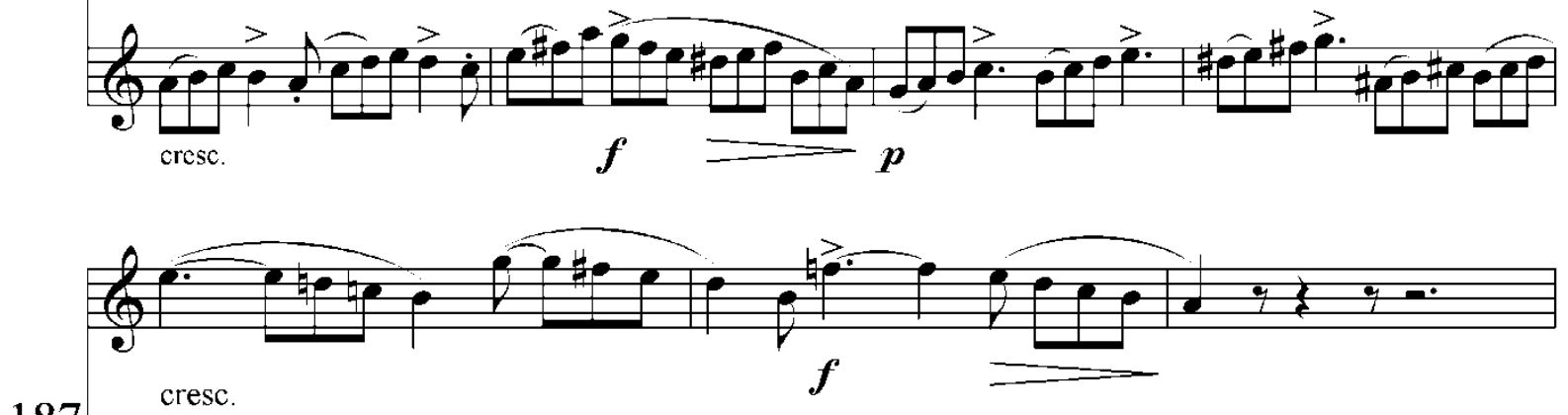

187

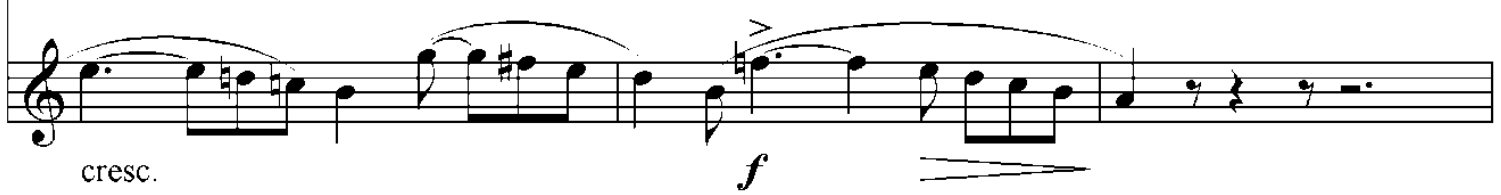

The articulations are very similar; however, in the Bärenreiter edition adds staccato

markings in measures 182 and 183. In both editions, measures 189 - 192 are an orchestral interlude which brings this section to an end.

The next five subsections are short eight measure sections in which there are several call and response phrases between the orchestra and the saxophone. The first (Figure 3.18) of these begins in measure 193 and continues through the downbeat of measure 201. 
Figure 3.18. Alexander Glazunov, Concerto in E-flat Major for Alto Saxophone and String Orchestra, Op. 109, measures 193 - 201: Articulations and placement of phrase markings.


In this section, there are many differences in phrasing. As has been the case throughout this work, Leduc has presented multiple slurs which aid in clarifying the harmony where Bärenreiter has indicated larger phrases which convey the flow of the melodic line.

With the exception of the accent on beat four of measure 198, there are no indications regarding articulation in the Leduc Edition. However, in the Bärenreiter edition, there are more detailed indications regarding specific articulations: the detached legato articulations in measures 195 and 196, the staccato in measure 197, the accent in measure 198, and the legato markings in measures 199 and 200.

Figure 3.19 illustrates measures 201 - 208; this section overlaps with the previous one at measure 201. 
Figure 3.19. Alexander Glazunov, Concerto in E-flat Major for Alto Saxophone and String Orchestra, Op. 109, measures 201 - 208: Articulations and placement of phrase markings.
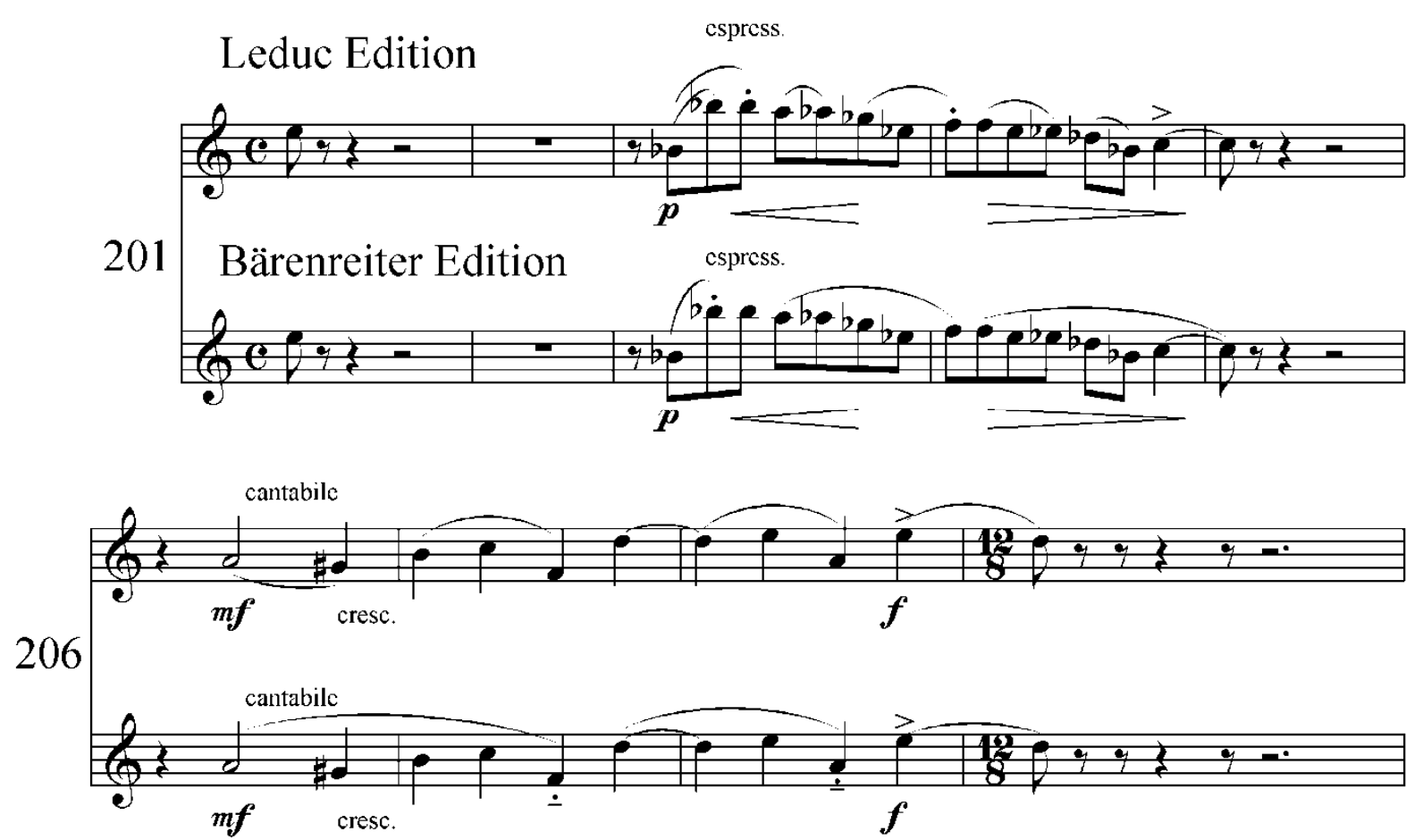

Again, the phrase and articulation indications in each edition are quite different. In measures

203 - 205 of the Leduc edition, there are six small gropus of slurred notes, two staccato

markings, and an accent. These same measures in the Bärenreiter edition have three larger

groupings indicated and only one specified articulation, the staccato in measure 203. The same

type of phrasing differences are also present in measures 206 - 209. The vertical and horizontal

approaches by Leduc and Bärenreiter respectively continue in this section. Bärenreiter has

indicated detached legato markings in measures 207 - 208 which are not in the Leduc edition.

Measure 209 marks the end of this section and the beginning of the next.

Measures 209 - 216 are primarily orchestral passages without the soloist. However, the phrasing and articulation in the limited saxophone passages (Figure 3.20) are quite different. 
Figure 3.20. Alexander Glazunov, Concerto in E-flat Major for Alto Saxophone and String Orchestra, Op. 109, measures 209 - 216. Articulations and placement of phrase markings.

Leduc Edition

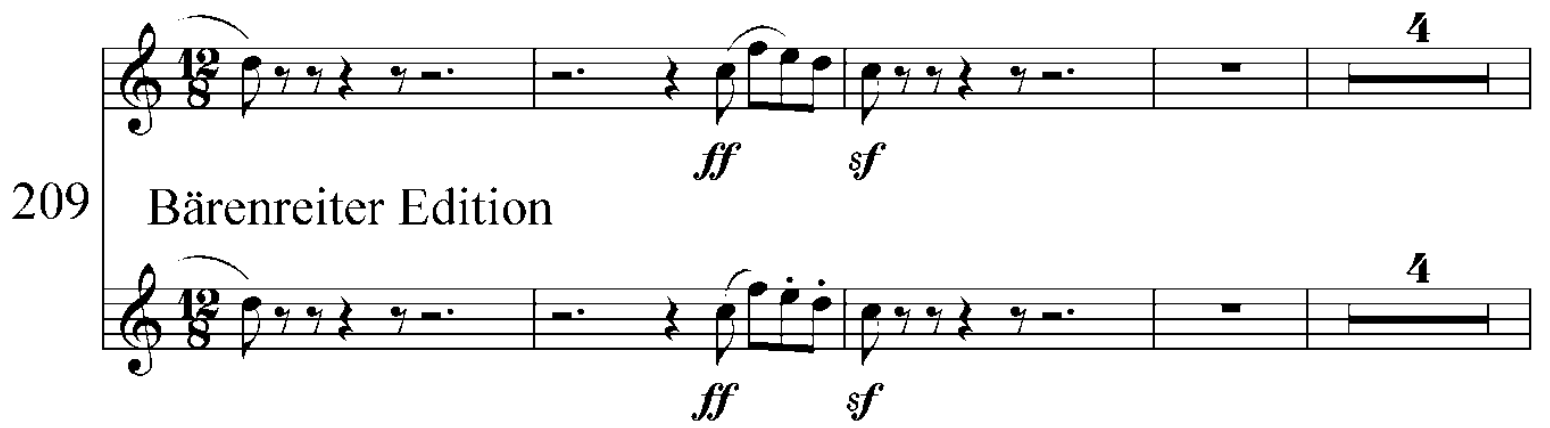

The articulation markings in the two editions are slightly different: in the Bärenreiter edition the last two eighth notes in measure 210 are marked staccato.

The last of the short eight measure subsections begins in measure 217 and ends at measure 224 (Figure 3.21). The same phrasing discrepancies are present in this section. Specific articulations are notated in the Bärenreiter edition, such as the detached legato markings in measures 219 and 223 and the legato marking in measure 222. There are no specific indications for articulation in the Leduc edition.

Figure 3.21. Alexander Glazunov, Concerto in E-flat Major for Alto Saxophone and String Orchestra, Op. 109, measures 217 - 224: Articulations and placement of phrase markings.

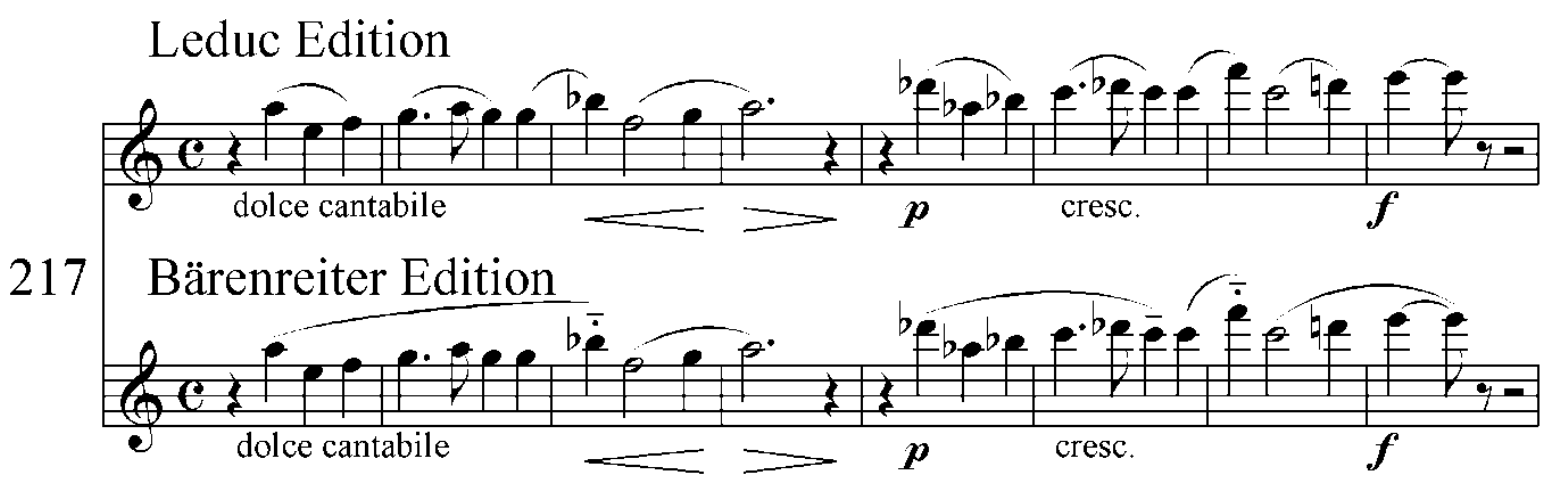


The next subsection, measures 225 - 235, begins with the orchestra; the saxophone does not enter until measure 227. The phrase markings differ significantly between the two sections (Figure 3.22).

Figure 3.22. Alexander Glazunov, Concerto in E-flat Major for Alto Saxophone and String Orchestra, Op. 109, measures 225 - 235: Articulations and placement of phrase markings.
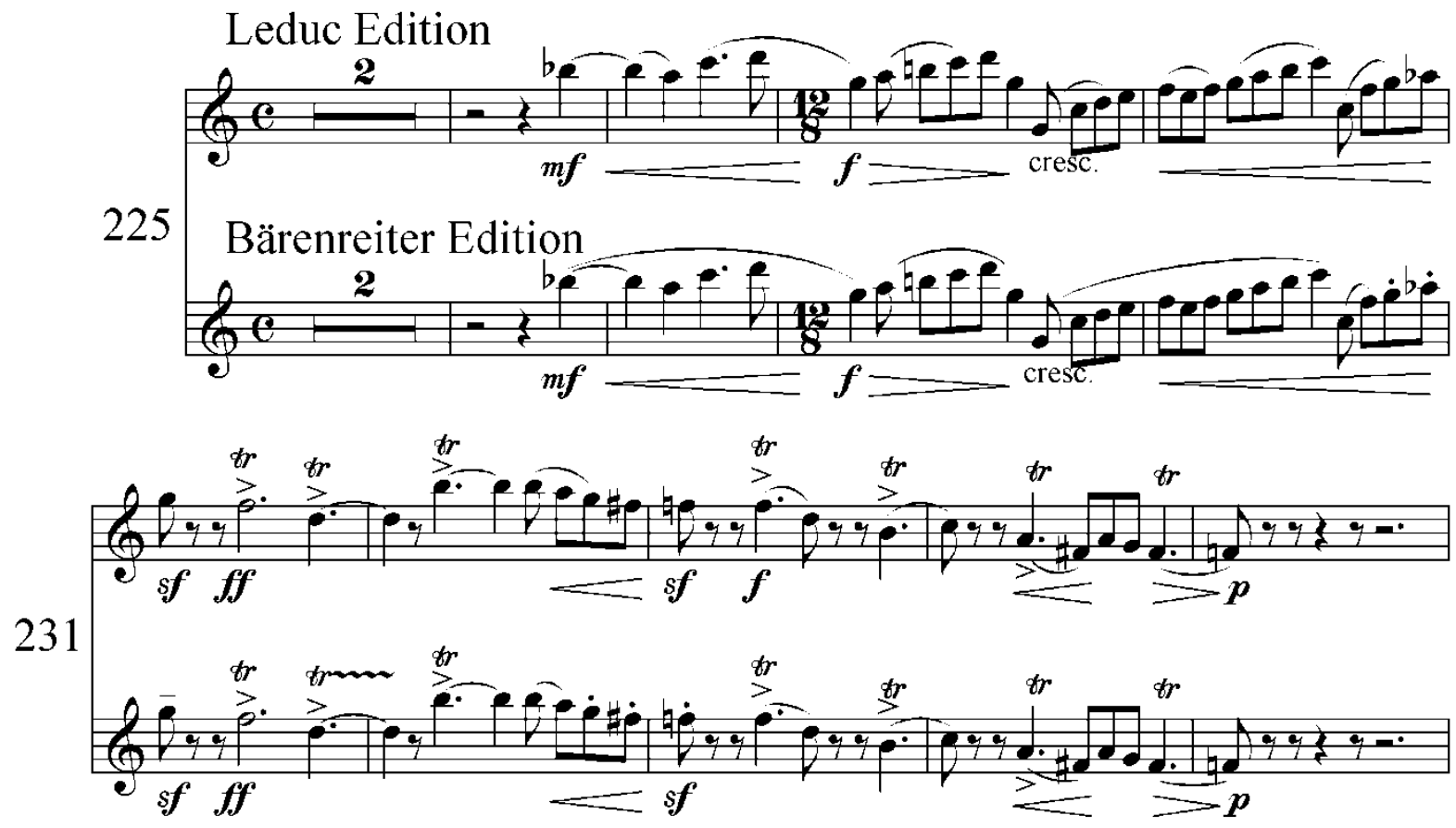

In measures 227 - 230 Leduc has divides the phrases into multiple slurs in order to bring out the angularity of the line. Bärenreiter indicates longer slurs for a more sostenuto character.

The Bärenreiter edition has staccato markings in measures 230 and 232 and the legato in measure 231 are articulations which are not indicated in the Leduc edition. The trill on the D dotted quarter note in measure 231, that carries over into measure 232 is clearly specified to carry through the end of the quarter note on the downbeat of measure 232 in Bärenreiter's edition. The trill is not as specific in the Leduc edition; as a result, the exact length of the trill is not consistently interpreted, as some performers trill through the quarter note on beat one of 
measure 232 while others end the trill on the downbeat of measure 232. The one dynamic difference in this section is the forte marking in measure 233 of the Leduc edition; this indication is not present in the Bärenreiter edition.

The section beginning in measure 236 - 253 (Figure 3.23) is a prime example of the two very different approaches to phrase structure which have been present through the entire work. In order to clearly define the changes in harmony, the Leduc edition is divided into multiple slurs. Bärenreiter, however, has clearly indicated the large overall phrase for a broad singing character. Articulation in this section has substantial disagreement as well. The accent on the downbeat of measure 239 in the Leduc edition is not present in the Bärenreiter edition. Bärenreiter has indicated several articulations which are not marked in the Leduc edition: they include: staccato markings in measures 238, 239, 242, and 243; and detached legato indications in measures 240 and 246. The Bärenreiter edition also includes breath marks in measures 244 and 248. 
Figure 3.23. Alexander Glazunov, Concerto in E-flat Major for Alto Saxophone and String Orchestra, Op. 109, measures 236 - 253: Articulations and placement of phrase markings.
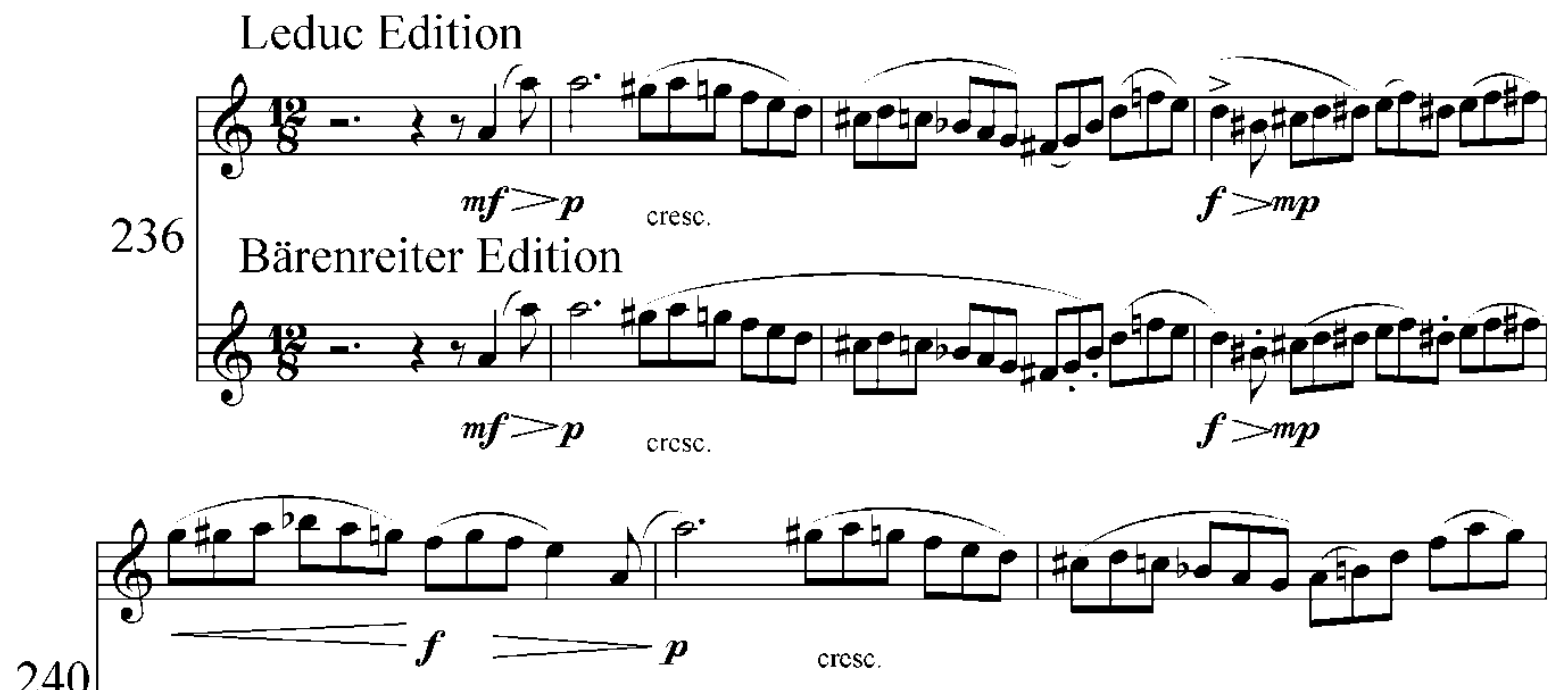

240
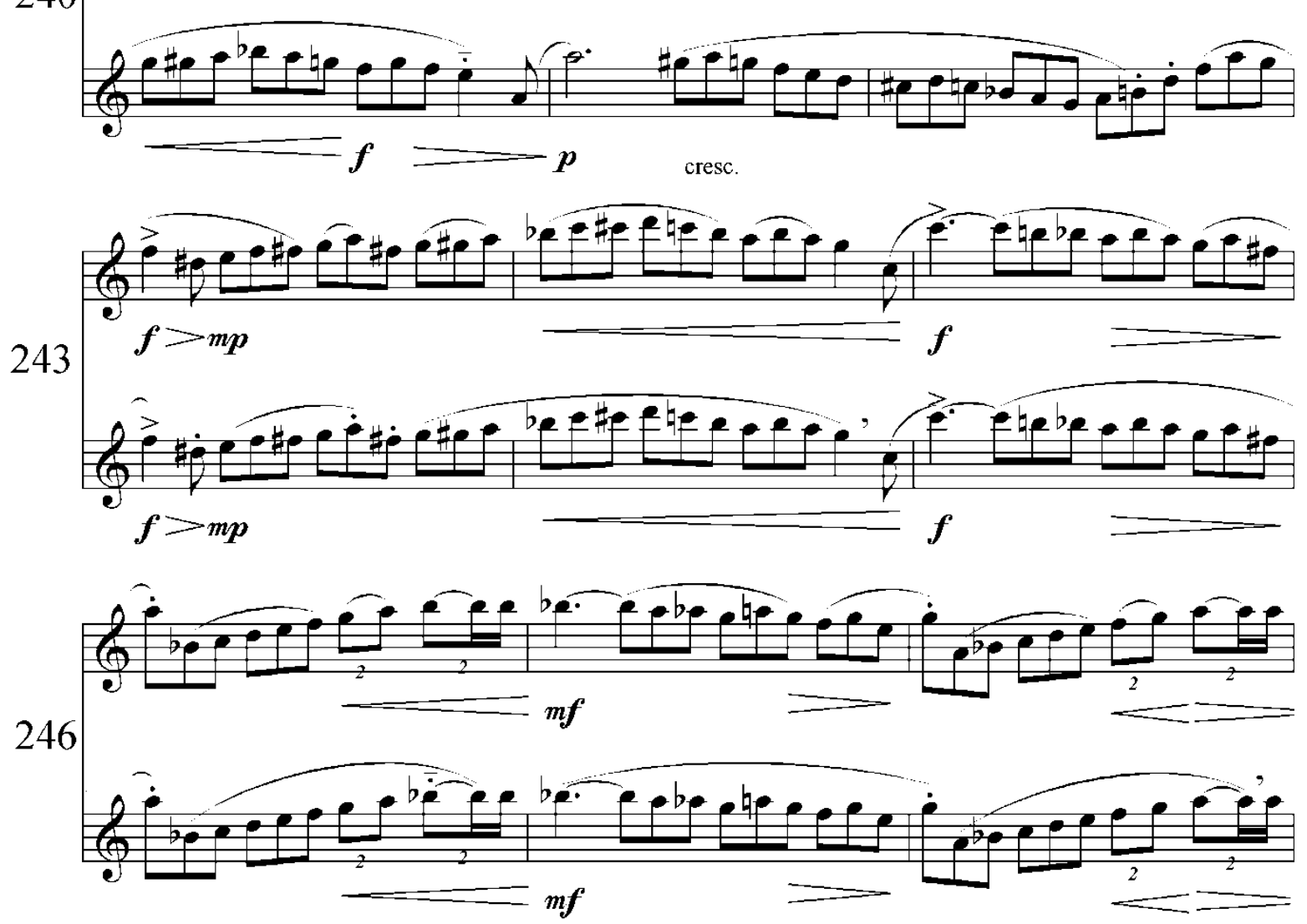

Unlike the first twelve measures of this section, there is very little difference between the two editions in the last five measures of this section; the phrasing and dynamics are identical. 
The only difference lies in the staccato indications in measures 249 - 251 of the Bärenreiter edition (Figure 3.24).

Figure 3.24. Alexander Glazunov, Concerto in E-flat Major for Alto Saxophone and String Orchestra, Op. 109, measures 249 - 253: Articulations and placement of phrase markings.
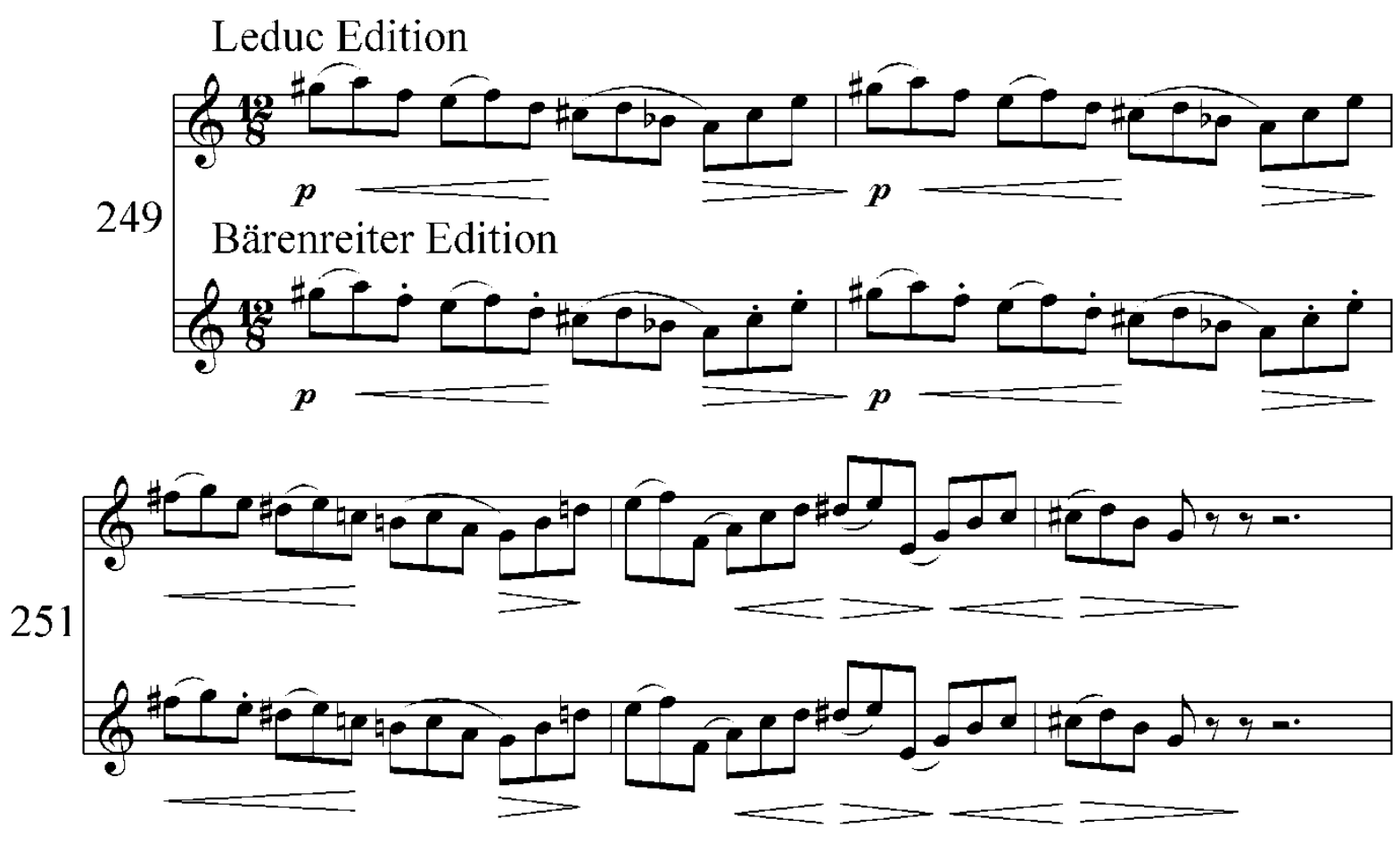
After a six measure orchestral interlude (measures 253 - 258), the saxophone enters on beat two of measure 259. The section beginning in measure 259 and ending on the downbeat of measure 277 is in two parts, the first part (Figure 3.25) begins at measure 259 and ends at measure 268; the second part (Figure 3.26) begins at measure 269 and ends at measure 277.

Figure 3.25. Alexander Glazunov, Concerto in E-flat Major for Alto Saxophone and String Orchestra, Op. 109, measures 259 - 268: Articulations and placement of phrase markings.
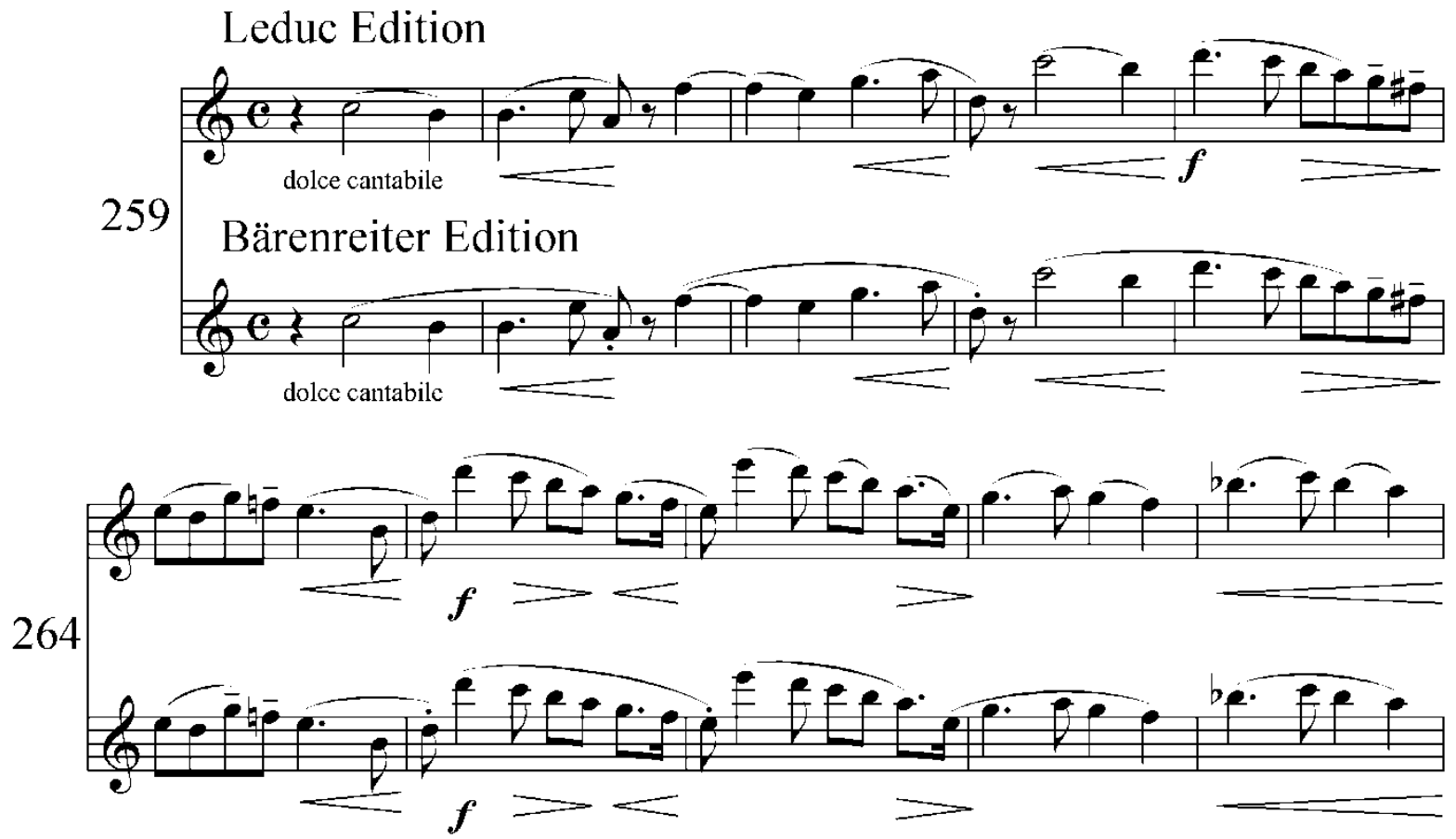

The phrasing in this section differs between the two editions. As has been the case throughout the Concerto, the phrase indications in the Leduc edition are grouped into very small groups of notes and the phrases in the Bärenreiter edition are longer. The articulation also differs, as the staccato indications in measures 260, 262, 265, and 266 of the Bärenreiter edition are not present in the Leduc edition; the same is true for the legato marking over the $G$ in measure 264. There is also a slight difference in dynamic markings. The Bärenreiter edition does not include the forte marking in measure 263 that is present in the Leduc edition. 
The second part of this section spans measures 269 to the downbeat of measure 277 . The only difference between the two editions in this part of the work is in the phrase indications; again, these show Leduc’s vertical approach and Bärenreiter’s horizontal approach.

Figure 3.26. Alexander Glazunov, Concerto in E-flat Major for Alto Saxophone and String Orchestra, Op. 109, measures 269 - 267: Articulations and placement of phrase markings.

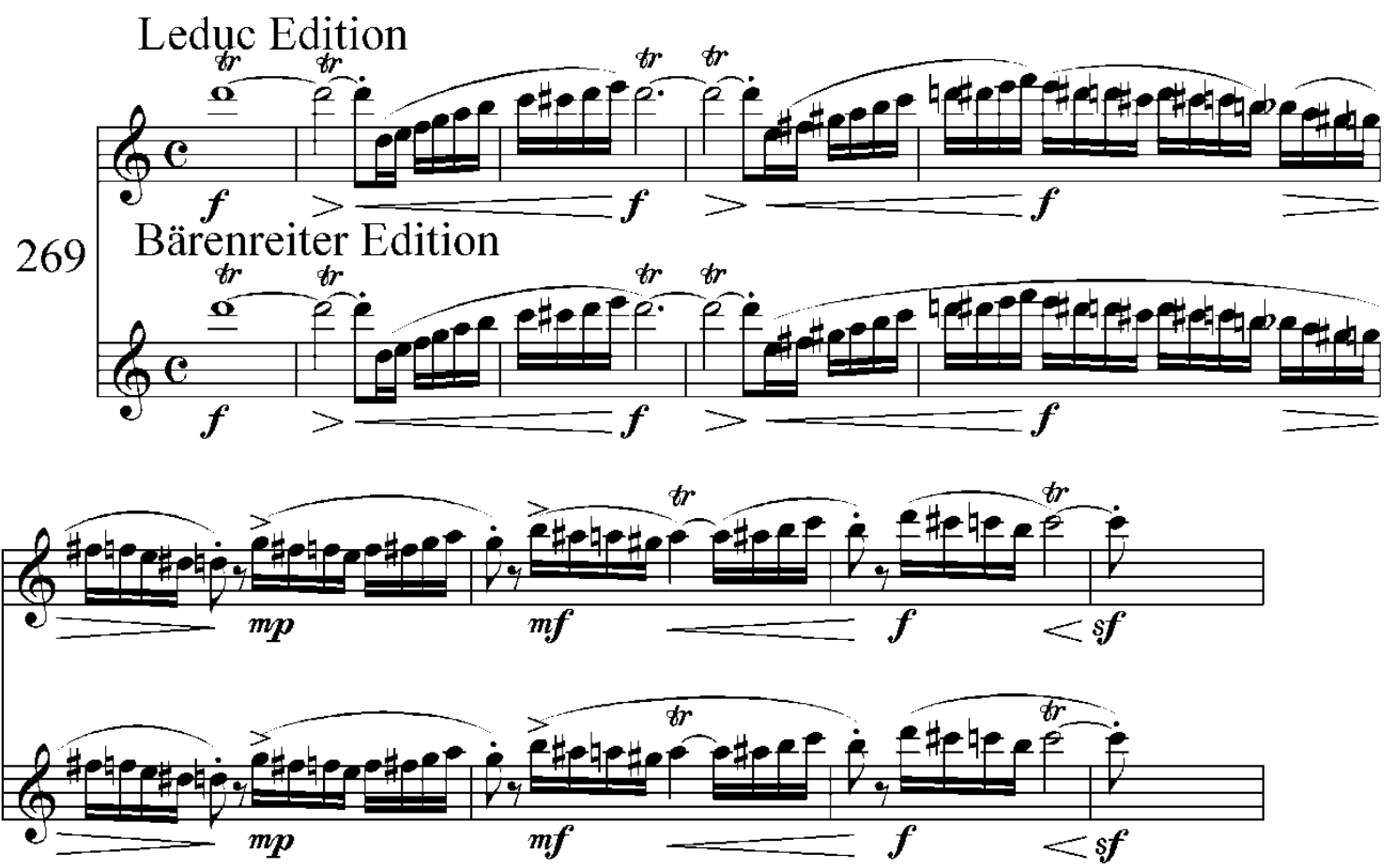

The next subsection begins on beat two of measure 277 and comes to an end at measure 281. This excerpt is virtually identical in both editions, the only difference being the notation regarding articulation of the quarter notes on beat four of measures 278 and 280 . In the Leduc edition, these notes are marked with accents and in the Bärenreiter edition these are marked with accented legato indications.

Measures 281 through the downbeat of measure 285 make up the next small section (Figure 3.27); as has been the case throughout this work, the difference between the two editions in these measures lies in the slur and phrase markings. 
Figure 3.27. Alexander Glazunov, Concerto in E-flat Major for Alto Saxophone and String Orchestra, Op. 109, measures 281 - 285: Articulations and placement of phrase markings.

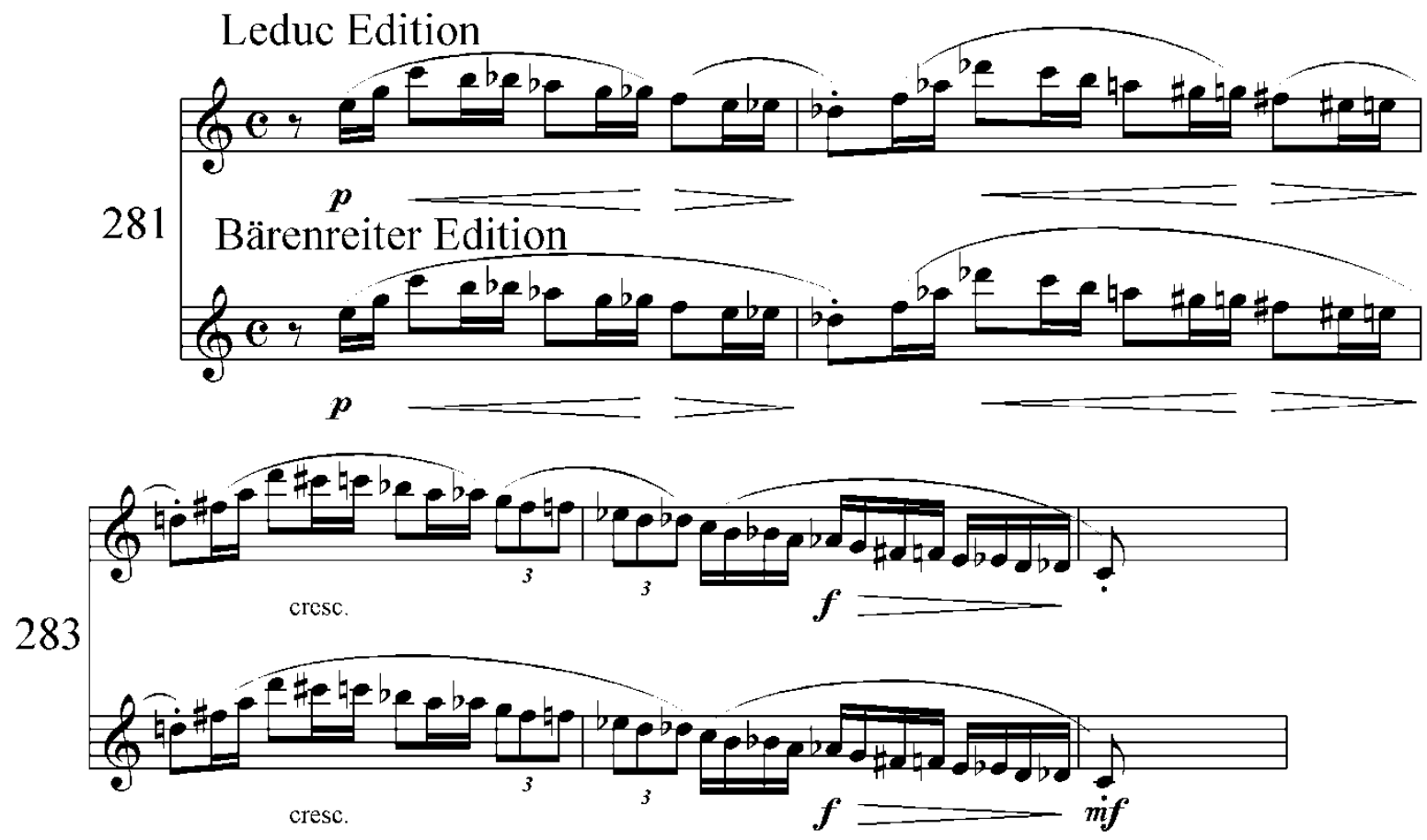

Also, the mezzo forte indication under the last eighth note of this section in the Bärenreiter

edition is not in the Leduc edition. Following these four measures, the next section (measure 285 beat two through the downbeat of measure 289) contains staccato eighth note octaves which descend chromatically. Aside from the mezzo forte indication on the downbeat of measure 289 of the Bärenreiter edition, there is no variance between the two editions in these measures.

Beginning on the second half of beat one of measure 289 to the downbeat of measure 293 (Figure 3.28) the difference between the editions is in the dynamic markings. 
Figure 3.28. Alexander Glazunov, Concerto in E-flat Major for Alto Saxophone and String Orchestra, Op. 109, measures 289 - 293: Dynamic markings.

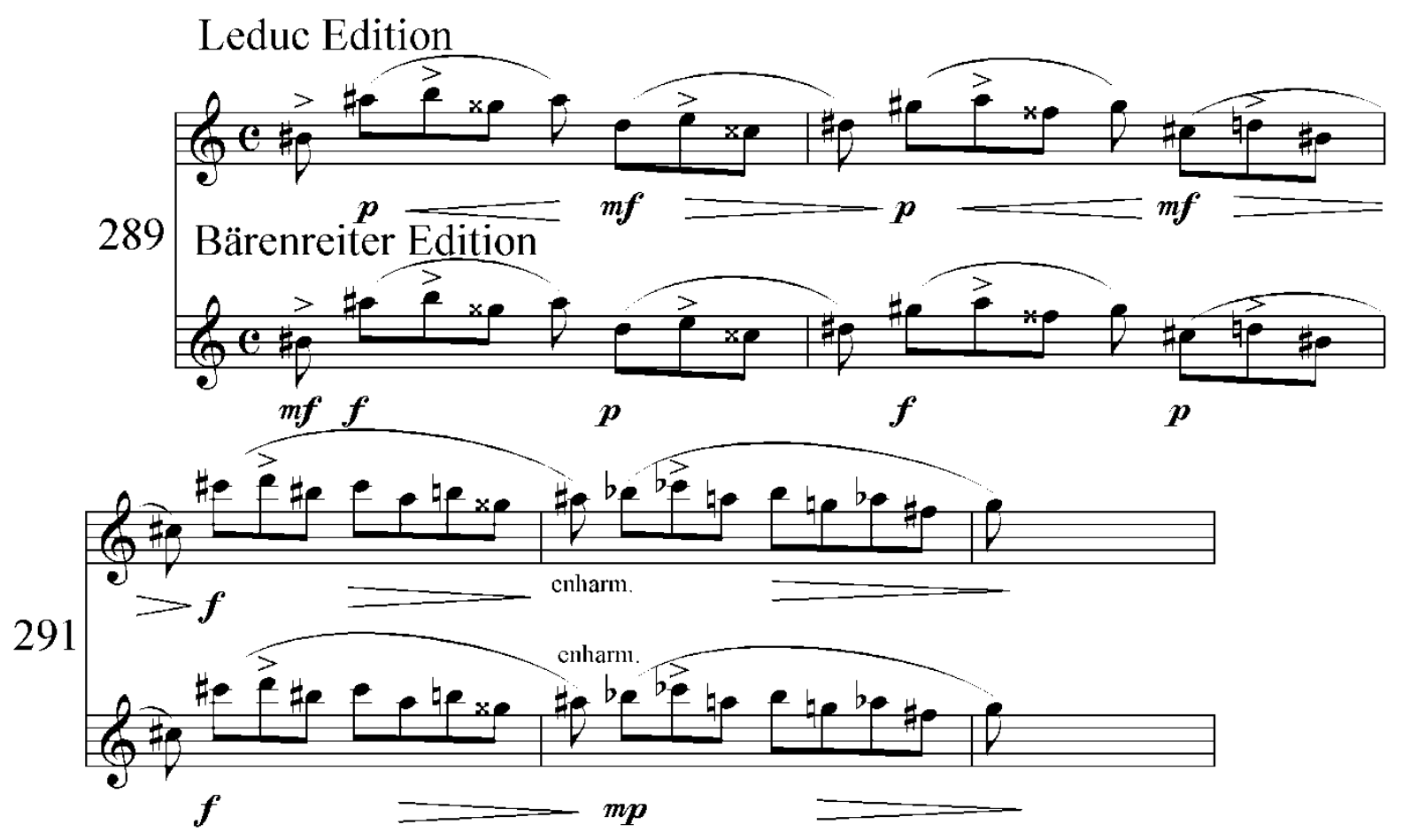

The major difference regarding dynamics is in the sequence in measures 289 through the downbeat of measure 291. In the Leduc edition, this section begins with a piano indication and crescendos to mezzo forte and decrescendos back to piano. In the Bärenreiter edition, the dynamics are abrubtly juxtaposed as the sequence alternates between forte and piano. The last two measures of this section are very similar with the only difference being the mezzo piano indication in the Bärenreiter edition in measure 292.

Beat two of measure 293 through the downbeat of measure 301 marks the next subsection (Figure 3.29). There are many differences in phrasing with Leduc breaking the phrases into multiple slurs and Bärenreiter indicating longer slurs. 
Figure 3.29. Alexander Glazunov, Concerto in E-flat Major for Alto Saxophone and String Orchestra, Op. 109, measures 293 - 300: Articulations and placement of phrase markings.

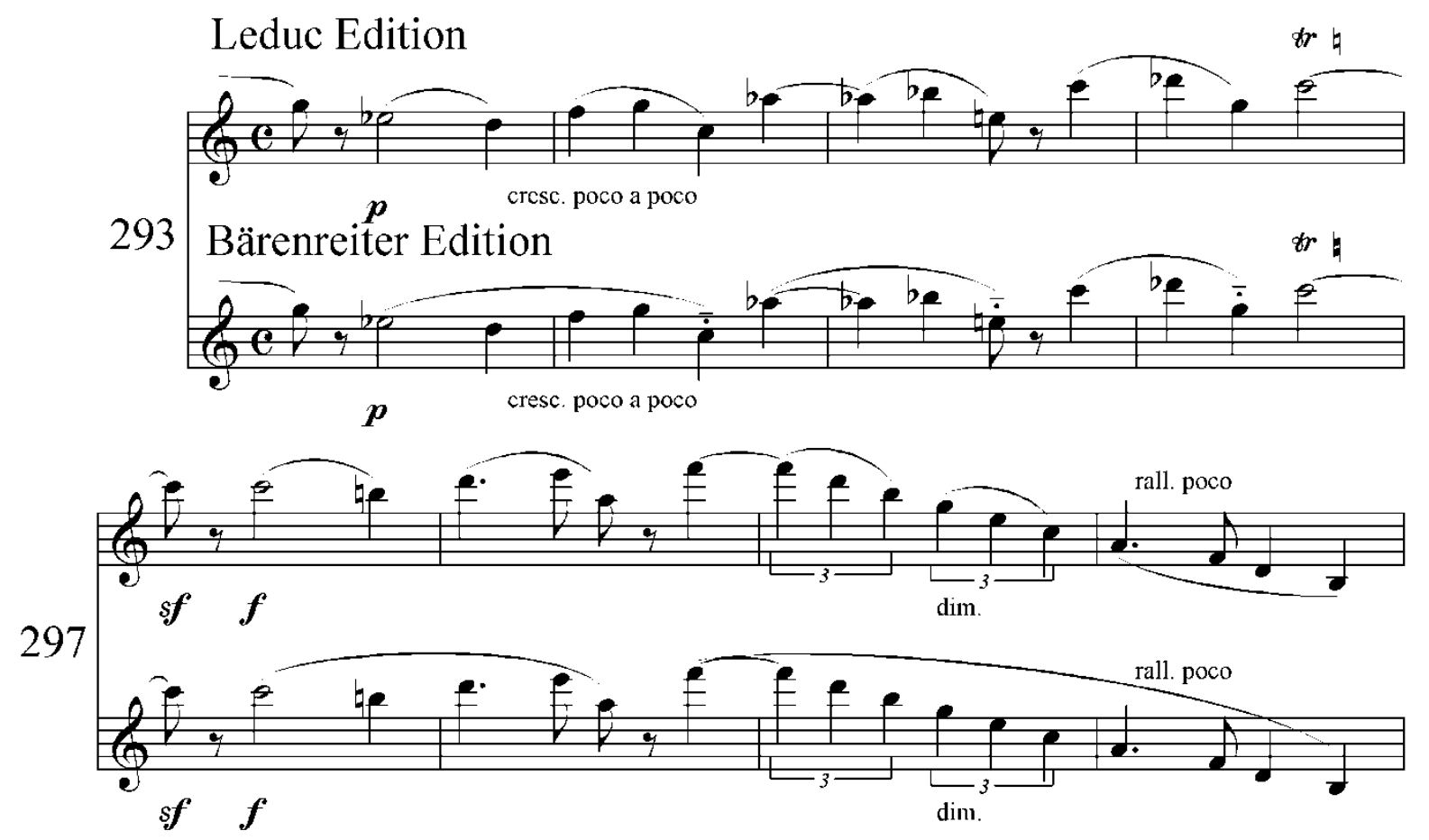

In the Bärenreiter edition, specific articulations have been indicated with detached legato markings in measures 294, 295, and 296.

In both of the editions, the next three sections of the work are almost identical. The first of the three begins in measure 301 and continues to the downbeat of measure 305, the only difference in this section is that the dotted quarter note on beat three of measure 302 is accented in the Bärenreiter edition and is not in the Leduc edition. The second of the three begins on beat two of measure 305 and ends on the downbeat of measure 309. In this section, staccato notes are indicated by Bärenreiter in the following measures: 305, 306, 307, 308; these indications are not present in the Leduc edition. The last of these sections, measures 309 through the downbeat of 314, is very similar in both editions. The only difference is regarding phrasing in measures 311 - 312 (Figure 3.30), reflecting shorter groupings in the Leduc edition and primarily longer in the Bärenreiter edition. 
Figure 3.30. Alexander Glazunov, Concerto in E-flat Major for Alto Saxophone and String Orchestra, Op. 109, measures 211 - 312: Articulations and placement of phrase markings.
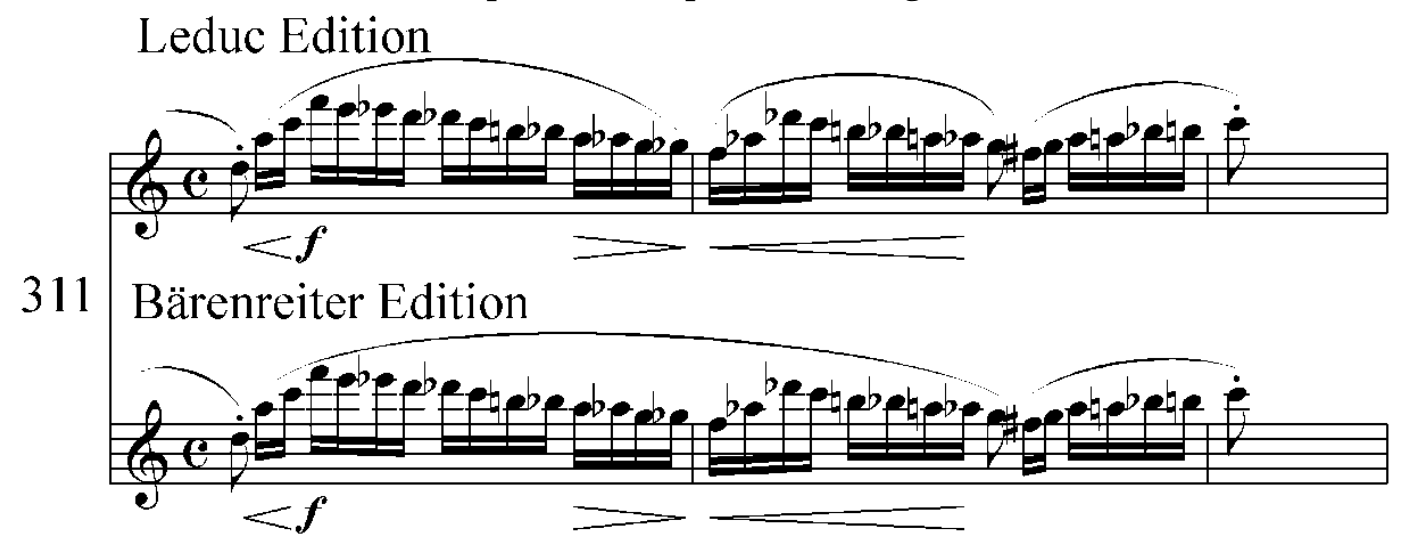

Leduc has again presented smaller groups of slurred notes and Bärenreiter larger ones. This presentation of the vertical and horizontal approaches to phrase structure by Leduc and Bärenreiter has been consistent throughout the work.

The final section of the Concerto, measures 313 - 329, contains significant variance between the two editions beginning with measures 316 - 320 (Figure 3.31). Differences in slur placement exist in measures 316 and 319 - 320. Also, the placement of the accents in measure 317 is different: the quarter note on beat three is accented in measure 317 of the Leduc edition while it is not in the Bärenreiter edition. The quarter note on beat four of measure 317 in the Bärenreiter edition is accented; this note is not accented in the Leduc edition. 
Figure 3.31. Alexander Glazunov, Concerto in E-flat Major for Alto Saxophone and String Orchestra, Op. 109, measures 316 - 320: Articulations and placement of phrase markings.

Leduc Edition

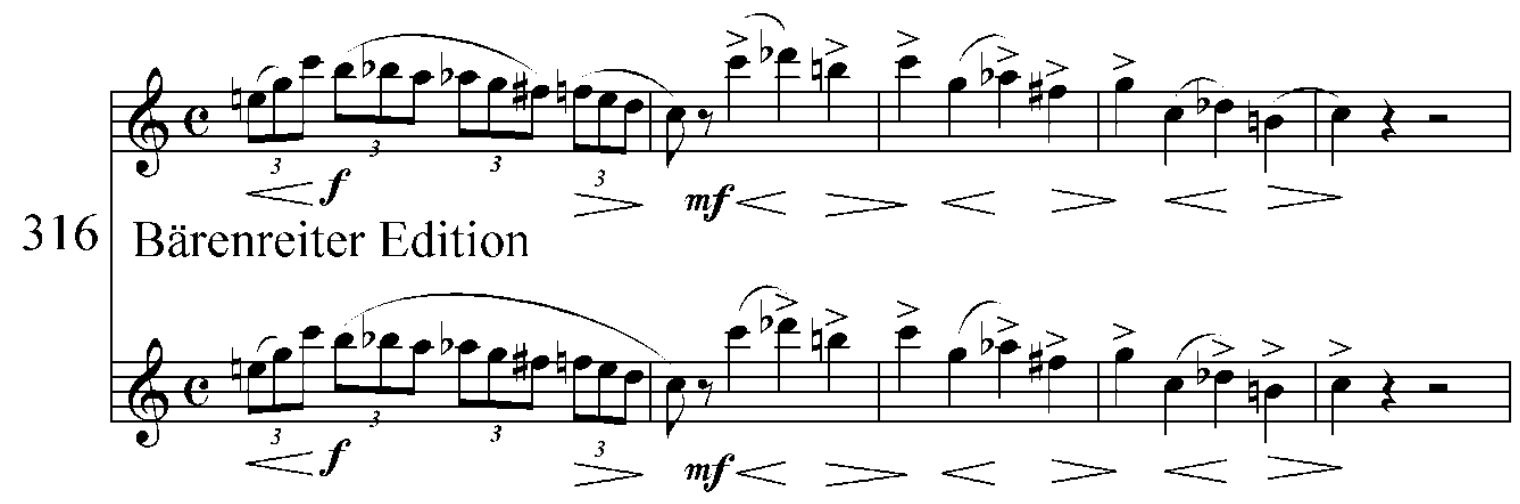

Figure 3.32 presents further changes that exist in the final measures (324 - 329).

Beginning with measure 324, beat four is of particular interest: in the Leduc edition, the saxophonist has the choice to play the altissimo $G$ or the lower B to $C$ figure, yet in the Bärenreiter edition indicates only the altissimo G. The two sixteenth notes on beat three of measure 325 are tongued in the Leduc edition; in the Bärenreiter edition these notes are slurred. In measure 326, the sixteenth notes on the "and" of beat one are slurred in the Leduc edition and are marked as tongued with staccato notes in the Bärenreiter edition.

The melodic content in the last three measures also differs between the two editions. The first two beats of measure 327 are comprised of an eighth note an eighth rest and a trilled quarter note in the Leduc edition, but in the Bärenreiter edition these beats are composed of a half note which is not trilled. Here, the Bärenreiter edition also indicates pesante poco. In measure 328 of the same edition, there is a piano marking, which is not in the Leduc edition, under the low $\mathrm{C}$ on beat one. 
Figure 3.32. Alexander Glazunov, Concerto in E-flat Major for Alto Saxophone and String Orchestra, Op. 109, measures 324 - 328: Articulations, placement of phrase markings, and altissimo notes.


The last figure (Figure 3.33), which starts on beat two of measure 328, is different in each edition. In the Leduc edition it is a short gesture which ends on beat three of measure 328, the saxophone ends this gesture before the orchestra plays the final notes. In the Bärenreiter edition, this figure begins on beat two of measure 328 and ends on beat one of measure 329; the saxophone and orchestra end together. Leduc presents this final gesture with an " $8 a$ ad. lib." indication, Bärenreiter presents this gesture with " $8 v a$ " indication. In the Leduc edition, the saxophonist has the option to play the final two notes as written or an octave higher in the altissimo register. However, according to the Bärenreiter edition, proficiency in the altissimo register is required. 
Figure 3.33. Alexander Glazunov, Concerto in E-flat Major for Alto Saxophone and String Orchestra, Op. 109, measures 328 - 329: The final gesture.

\section{Leduc Edition}

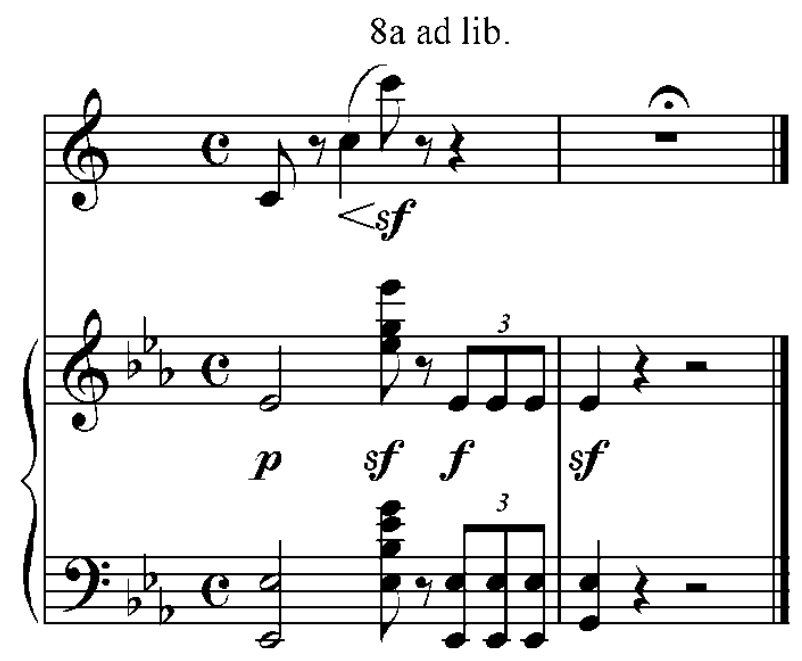

\section{Bärenreiter Edition}

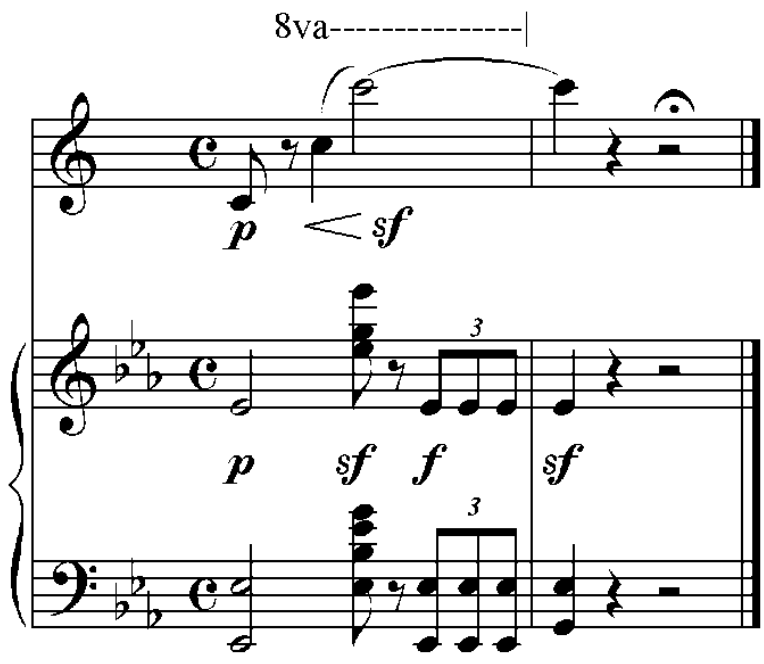

The difference between the two editions of the solo saxophone part of this Concerto is substantial. Extensive variance in phrasing and articulation and the inclusion of multiple cadenzas make up the majority of the differences between these two editions. Other less frequent discrepancies are in dynamic indications, the style of attacks of certain notes, indication of specific fingerings, breath marks, and, in a few cases, actual differences in the melodic material. As a result of these differences, new possibilities for musical interpretation of this standard work of saxophone literature are now available.

\section{The Orchestra Score and the Piano Reduction}

The Bärenreiter and Leduc editions of the orchestra score are exactly identical. However, there have been some very subtle changes made to the piano reduction. For example, passages have been moved to a different clef in order to make the printed part easier to read, melodic lines which were doubled in octaves in the Leduc edition have been reduced to a single line, many of the chords in the Bärenreiter edition are voiced without the pitch doubling found in the Leduc 
edition, and in some cases the melodic lines have been altered. Prior to Bärenreiter's publication, and in correspondence with the author, Carina Rascher referred to the piano reduction: 'Since the piano part was extremely 'unpianistic,' there will be a revised piano reduction, ${ }^{39}$ and subsequently, changes were made to make the piano reduction more idiomatic.

\footnotetext{
${ }^{39}$ Carina Rascher, e-mail message to Christopher D. Mickel, May 28, 2010.
} 


\section{Chapter 4: Conclusions}

\section{Summary of Differences between the Concerto's Two Editions}

It is clear that the Leduc and Bärenreiter editions of the saxophone solo part differ significantly. The most apparent discrepancies are related to phrasing, articulation, and the cadenza, with other less frequent variance in dynamic indications, the style of note attacks, indication of specific fingerings, breath marks, and, in a few cases, actual differences in the melodic material.

In the period between the work’s completion and its publication, Glazunov made several changes to the melodic content of the work. The Bärenreiter edition presents the melodic content as it was originally presented in the autographed score that Glazunov gave to Rascher upon completing the work in 1934. It was from this score that Rascher initially performed the work's premiere. The Leduc edition, published in 1936, is the product of Glazunov’s revisions. According to a previously unpublished note by Rascher, dating from the 1980s, Glazunov made changes to the Concerto before the publication process [by Leduc]. ${ }^{40}$ Correspondence between Glazunov and Rascher documents these changes: one of Glazunov’s letters to Rascher dated October 2, 1934, explains a change in the last figure in measures 327 - 329 (Figure 4.1) which is different that the ending gestures in the Leduc edition and the Bärenreiter edition. In this letter Glazunov explains to Rascher that he had “....altered the penultimate bar as follows to avoid interrupting the phrase in the main part of my saxophone concerto: I find it much more logical!" 41 Glazunov would again alter this phrase; this final change is noted in the difference between the two editions presented in Figure 3.32. He announced to Rascher on February $28^{\text {th }}$,

\footnotetext{
${ }^{40}$ Alexander Glazunov, Concerto In E-Flat Major for Alto Saxophone and String Orchestra (Kassel, Germany: Bärenreiter, 2010), XIV.

${ }^{41}$ Glazunov, Concerto in E-Flat Major, (Kassel, Germany: Bärenreiter, 2010), XIV.
} 
1935, that the final gesture had again been changed to the version indicated in the Leduc

Edition. $^{42}$

Figure 4.1. Alexander Glazunov, Concerto in E-flat Major for Alto Saxophone and String Orchestra, Op. 109, measures 327 - 329. Revision made by Glazunov, October $2^{\text {nd }}, 1934$.

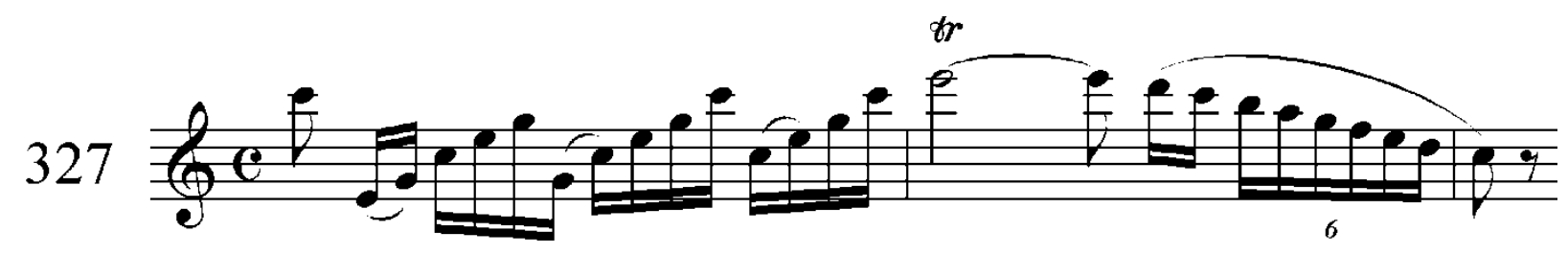

Further evidence that changes were made is present in measures 176 - 178 (Figure 3.16).

However, it is unclear as to exactly when Glazunov made these changes which, after comparing with his autographed score, Sigurd Rascher addressed as follows:

But it is evident that before the first printing this and that were changed in the solo part. In the three measures before rehearsal number 24 [measures 176 178 in the manuscript are no eighth-rests, but octaves, just as in the previous measures. $^{43}$

Other discrepancies in the melodic material exist in measures 324 and 328 in the form of optional lower pitches to substitute for the notes written in the altissimo register. Upon noticing these changes, Sigurd Rascher asked Glazunov why he made them. According to Rascher:

Glazunov told me that the ranking local [Paris where Glazunov lived at the time] saxophone player had visited him, and on that occasion learned of the young player from Copenhagen [Rascher] and his excursions into the high register. Whereupon the visitor remarked, "Nous ne faisons d'choses comme ca, nous avons l'ecole Parisienne" ["We wouldn't do that, we have Parisian Schooling." Trans. Sigurd M. Rascher] ${ }^{44}$

At the time of the composition of this work, Rascher was the only saxophonist who had cultivated the altissimo register, and had refined it to a point suitable for use in classical music. The Parisian saxophonists of the day, including Marcel Mule and his students,

\footnotetext{
${ }^{42}$ Glazunov, Concerto in E-Flat Major, (Kassel, Germany: Bärenreiter, 2010), XIV.

${ }^{43}$ Sigurd M. Rascher, “Alexander Glazunov: Concerto pour Saxophone avec l’orchestre de cordes.” Saxophone Symposium Volume XIII No.2 (Spring 1988): 17.

${ }^{44}$ Rascher, “Alexander Glazunov,” 17.
} 
simply did not play in the altissimo register. It is likely that Glazunov added these optional substitute pitches for the altissimo notes to make the piece more easily playable and also concurrent with playing trends of that time.

The Bärenreiter edition includes three different cadenzas. The first cadenza (Figure 3.14) is a truncated version of the cadenza issued in the Leduc edition. This cadenza is essentially the original cadenza present in the autographed score. According to Carina Rascher, it is “...the original cadenza written in the manuscript (much shorter)."45 Rascher preferred his own cadenza (Figure 3.15), of which Glazunov approved. Sigurd Rascher recalls his first rehearsal of the Concerto with Glazunov: "Even when I let on that I was none too happy with the cadenza and played my own for him, he listened to it a few times and meant it fit rather well, I should play it. [sic]"46 On February $28^{\text {th }}, 1935$, Glazunov notified Rascher that he had expanded his cadenza. ${ }^{47}$ This expanded cadenza (Figure 3.13) is the one present in the Leduc edition.

The phrasing, articulation, dynamic indications, the styles of note attacks of certain notes, indication of specific fingerings, and breath marks indicated in the Bärenreiter edition are intended to create a solo saxophone part which represents Rascher's approach to performing the work. Carina Rascher discusses these changes:

...the saxophone part as SMR [Sigurd M. Rascher] played it, with totally different phrasing, with the missing tones left off by Leduc [the octave passage in measures 176 - 178] and his, by Glazounov himself sanctioned version, of the cadenza [Rascher's cadenza Figure 3.15] and no AD [referring to the optional substitute pitches for the altissimo notes] for $\mathrm{G}$ and $\mathrm{C}$ at the end. ${ }^{48}$

Carina Rascher discusses the phrasing, articulation, and slur markings notated in the Bärenreiter edition: “The SMR [Sigurd M. Rascher] solo part is taken from the Urtext [sic]...The phrasing,

\footnotetext{
${ }^{45}$ Carina Rascher, e-mail message to Christopher D. Mickel, May 28, 2010.

${ }^{46}$ Glazunov, Concerto in E-Flat Major, (Kassel, Germany: Bärenreiter, 2010), XIV

${ }^{47}$ Glazunov, Concerto in E-Flat Major, (Kassel, Germany: Bärenreiter, 2010), XIV

${ }^{48}$ Carina Rascher, e-mail message to Christopher D. Mickel, May 28, 2010.
} 
articulation, and slur markings were taken from his [Sigurd Rascher's] performance solo part, and the recollections of his playing, from my memory." ${ }^{49}$

The variance between the Leduc and the Bärenreiter editions of the solo saxophone part can be clearly explained. The majority of the differences are a result of revisions made by Glazunov in the two years (1934 - 1936) between the composition of the work and its subsequent publication. Other differences are a result of the addition of Rasher's own cadenza and Bärenreiter's effort to create a solo saxophone part that reflects Rascher's interpretation. These changes offer new performance options for saxophonists studying this essnetial part of the classical saxophone repertoire.

\section{The Orchestra Score}

The Leduc and Bärenreiter editions of the orchestra score are identical. However, as he did with the saxophone solo part, Glazunov made some revisions before publication. The changes occur in two small sections of the cello part. The first change, four measures after rehearsal number 22, is in measures 165 through the downbeat of measure 169 (Figure 4.2):

Figure 4.2. Alexander Glazunov, Concerto in E-flat Major for Alto Saxophone and String Orchestra, Op. 109, measures 165 - 169. Cello part as it appears in the Leduc and Bärenreiter editions. con sord.

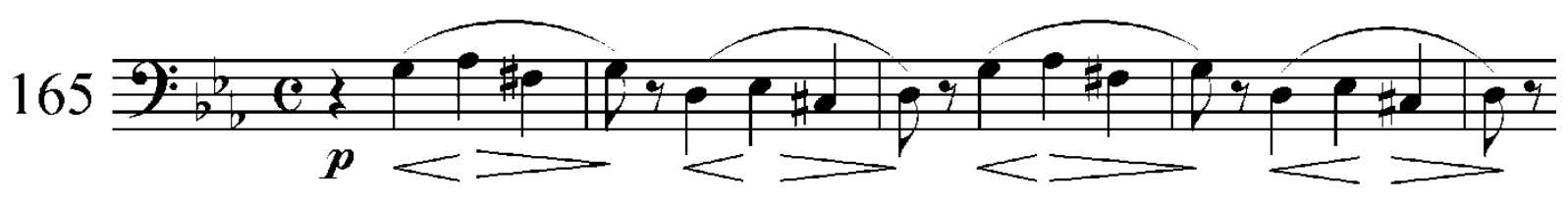

This passage from the cello part, found in the Leduc and the Bärenreiter editions, was indicated in the autographed score ${ }^{50}$ as a lead in to be played by the saxophone when the cadenza came to

\footnotetext{
${ }^{49}$ Carina Rascher, e-mail message to Christopher D. Mickel, January 23, 2011.
} 
an end. Glazunov made Rascher aware of these changes on February $28^{\text {th }}$, 1935; stating: “...the four measures [in the saxophone solo part] after rehearsal number 22 are replaced by muted cellos...”51 The autographed score also contains a different cello part (Figure 4.3):

Figure 4.3. Alexander Glazunov, Concerto in E-flat Major for Alto Saxophone and String Orchestra, Op. 109, measures 165 - 169. Cello part as it appears in the autographed score.

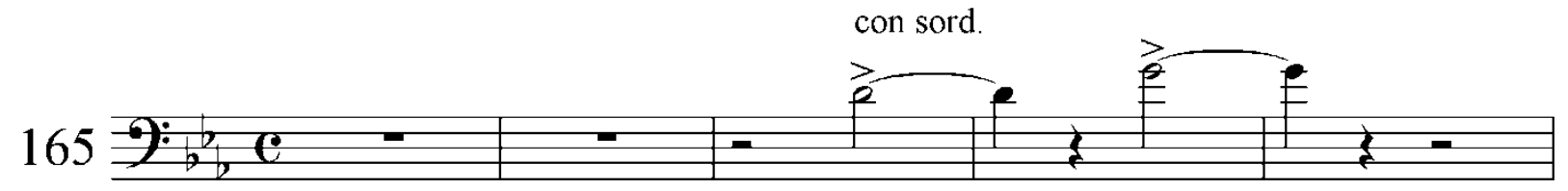

In the autographed score, the passage indicated in Figure 4.2 is crossed through in the saxophone part and written in the cello part over the passage presented in Figure 4.3.

The other change in the cello part begins two beats before rehearsal number 23 on beat three of measure 169 and continues through measure 178. According to the autographed score, ${ }^{52}$ the cellos rest during these measures. However, Glazunov added a pizzicato cello passage (Figure 4.4) before publication:

Figure 4.4. Alexander Glazunov, Concerto in E-flat Major for Alto Saxophone and String Orchestra, Op. 109, measures 169 - 178. Cello part as it appears in the Leduc and Bärenreiter editions.
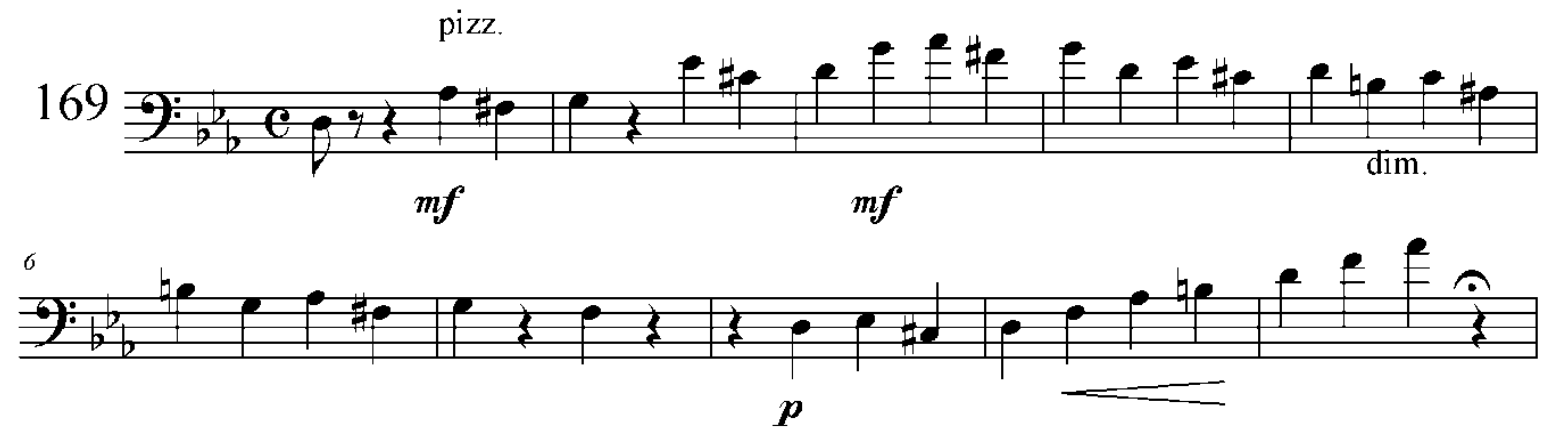

\footnotetext{
${ }^{50}$ Glazunov, Concerto in E-Flat Major, (Kassel, Germany: Bärenreiter, 2010), 39

${ }^{51}$ Glazunov, Concerto in E-Flat Major, (Kassel, Germany: Bärenreiter, 2010), XIV

${ }^{52}$ Glazunov, Concerto in E-Flat Major, (Kassel, Germany: Bärenreiter, 2010), 39
} 
This is another revision Glazunov announced to Rascher in the letter of February $28^{\text {th }}, 1935$.

Regarding these changes, Glazunov stated: “...three measures before rehearsal number 24 there are changes in the solo part [see Figure 3.16] and the cellos [Figure 4.4]...,53

These are the only revisions made to the orchestra score. All of these changes were made prior to publication and the material presented in the Leduc and the Bärenreiter editions is representative of these revisions. The Bärenreiter edition of the saxophone solo part represents the autographed manuscript and Sigurd Rascher's performances, while the Leduc edition represents Glazunov’s revisions. However, both editions of the orchestral score represent Glazunov’s revisions.

\section{Other Resources Related to Glazunov's Concerto}

There are other pedagogical and performance resources related to Glazunov’s Concerto: a Music Minus One edition, a new cadenza, and an alternate ending to the new cadenza ${ }^{54}$. The Music Minus One edition includes the solo part for Glazunov’s work (as it is presented in the Leduc edition) as well as the solo part for Earland von Koch’s Concerto for Saxophone and Orchestra in E-Flat Major. Also included are complete recordings of each work and play-along tracks (a performance with the saxophone track removed) which were recorded by Lawrence Gwozdz (a prominent saxophone performer and pedagogue and a student of Rascher) playing the saxophone solo with the Plovdiv Philharmonic Orchestra conducted by Nayden Todorov.

A fourth cadenza has been written by the contemporary French composer Christian Lauba. Lauba is known for writing non-traditional, contemporary saxophone literature which

\footnotetext{
${ }^{53}$ Glazunov, Concerto in E-Flat Major, (Kassel, Germany: Bärenreiter, 2010), XIV.

${ }^{54}$ Alexander Glazunov and Erland von Koch, Music Minus One Alto Saxophone, Glazunov/von Koch: Concertos in E-Flat Major (Elmsford, NY: Music Minus One, 2000).
} 
utilizes extended techniques: multiphonics, slap-tongue, tone-color trills, vibrato manipulation, flutter-tongue, key clicks, quarter tones, and altissimo; some of his works require the saxophonist to have mastered the technique of circular breathing. A notable example of this style is his Neuf études pour saxophone. However, Lauba has stepped out of the contemporary aesthetic for which he is well known and incorporated a more traditional approach in his cadenza for the Glazunov Concerto:

I composed the cadenza because Leduc thinks that the cadenza which is published is too short and of weak musical quality. Above all, it is not originally written by Glazounov but by Petiot. When I wrote my cadenza, my model was Glazounov's violin concerto, his symphonies, specially the 4th which is a masterpiece, but also the concertos by Tchaïkovski the cadenzas of which are so well written. His violin and his piano concertos (also the 2nd which is less famous). I wanted to introduce some genuine virtuosity in this cadenza and also to make it much longer so that the equilibrium of the form is more balanced. It amplifies the concerto. As for the construction, I use most of the main themes as in a "classical "cadenza by Mozart or Beethoven. The style is of course post-romantic but in a more "classical" way; Glazounov is not Tchaïkovski! ${ }^{55}$

This cadenza was composed for saxophonist Richard Ducros, and according to Lauba: “will be the 13th Étude 'de style' ${ }^{56}$ published by Leduc."57

Concert saxophonist Douglas O’Connor has added to Lauba’s cadenza. He has composed an alternate ending $^{58}$ (to the cadenza which begins on the penultimate staff line of Lauba’s cadenza. O’Connor has discussed the alternate ending: “I didn’t think the ending worked well for drawing the orchestra back in, so I made my own ending to Lauba's Glazunov cadenza. . .I had Lauba’s permission!”59

\footnotetext{
${ }^{55}$ Christian Lauba, e-mail message to Christopher D. Mickel, January 25, 2011.

${ }^{56}$ Christian Lauba, Cadence du Concerto pour Saxophone et orchestre à cordes d'Alexandre Glazounov: $13^{e}$ étude de style pour saxophone alto, (Paris: Alphonse Leduc, 2010).

${ }^{57}$ Christian Lauba, e-mail message to Christopher D. Mickel, January 25, 2011.

${ }^{58}$ Douglas O’Connor. “Ending to Lauba’s Glazunov Cadenza.” Score. 2010. Personal collection of Douglas O’Connor. Rochester NY.

${ }^{59}$ Douglas O’Connor, e-mail message to Christopher D. Mickel, January 14, 2011.
} 


\section{Closing Remarks}

Glazunov's Concerto for Alto Saxophone and String Orchestra is one of the most important works in the saxophone repertoire; it is frequently performed and is a standard requirement in saxophone curriculae around the world. The material contained in this research will provide saxophonists with a single source which clearly addresses the following: the circumstances relating to the genesis of Glazunov's work, a detailed comparative analysis of the published editions of the Concerto by Leduc and Bärenreiter, an explanation of the revisions made by Glazunov before the initial publication of the work, and a discussion of other sources related to the Concerto. Saxophonists will benefit from this research because it is currently the only single source which provides detailed information regarding these different aspects of this very important saxophone concerto.

The chapter containing the history of the Concerto provides an accurate account of the composition of Glazunov's work. Furthermore, the discrepancies in the accounts which address for whom the Concerto was written and who gave the premiere performance are examined and clarified. Lastly, the involvement of André Petiot, whose name appears as co-composer in the Leduc edition, is also examined and resolved.

Comparative analysis of the Leduc edition and the new Bärenreiter edition shows two very different approaches to performing the Concerto. With this new edition of this standard work now available, saxophonists can and should begin to explore new possibilities for musical interpretation. The comparative analysis contained provides saxophonists the opportunity to carefully examine both editions and decide how they want to perform the piece, or specific sections of it, based upon which persentation of the Concerto makes the most aesthetic and 
intellectual sense. As a result of this comparison, the author hopes new interpretations of this work will make their way into concerthalls.

In addition to the comparative analysis of the published editions of the Concerto, the author discusses the edits made by Glazunov in the time between the composition of the work in 1934 and its publication by Leduc in 1936. This two-year span between composition and publication highlights the relationship between the published editions and the work's autographed score. Although both published editios include the changes to the orchstra score, the Bärenreiter edition includes Rashcer’s inpterpretation, evidenced by the editorial markings. The Leduc edition includes Glazunov's edits which took place during the two years between its composition and publication.

When discussing the Bärenreiter edition of the saxophone solo part, Carina Rascher states, "The SMR [Sigurd M. Rascher] solo part is taken from the Urtext." ${ }^{\text {"0 }}$ Here, she refers to the autographed manuscript as the urtext for which Bärenreiter presents the solo part as Glazunov's initially envisioned it. The Leduc edition however, does contain Glazunov's later revisions; the phrasing, articulation, and placement of the slurs are very different than those indicated in the autographed manuscript. These differences in phrasing and articulation make up the vast majority of the differences between the published editions. A large number of the significant works in the saxophone repertoire are published by Leduc, and were influenced by Marcel Mule and his saxophone pedagagy defined at the Paris Conservatory. As a result of this Parisian influence, editing practices have become apparent and can be considered as a style associated with Leduc. Although is unclear as to exactly why these differences exist, it is possible that editors at Leduc applied their approach to notation to Glazunov's work creating an edition from which saxophonists have now performed since 1936.

\footnotetext{
${ }^{60}$ Carina Rascher, e-mail message to Christopher D. Mickel, January 23, 2011.
} 
The author does not consider the original score, the Bärenreiter edition, or the Leduc edition to be a definitive edition of this work for the following reasons: the original score and the Bärenreiter edition do not contain Glazunov's later revisions and the Leduc edition contains numerous changes to phrasing, articulation, and slur placement that were possibly not made by Glazunov. A difinitive edition of the work would have Glazunov's melodic revisions and the articulations identified in the autographed manuscript.

The discussion of other sources related to the Concerto provides information regarding pedagogical and performance resources related to the work. The first source is a Music Minus One ${ }^{61}$ edition which includes the saxophone solo part as well as a recording of the concerto and a play along track for study and practice. The second source is a cadenza written by Christian Lauba. This cadenza, which is a separate publication by Leduc, is longer and more virtuostic than those included in the Leduc and Bärenreiter editions. This is significant because saxophonists now have four cadenzas to consider and the author believes that saxophonists will decide based upon their own personal taste. However, some players, especially less experienced students, will not choose Lauba's cadenza because it is intended to be extremely virtuostic and as a result is very difficult; the author believes that less experienced students who are learning the Concerto should first learn Glazunov’s original cadenza, then Rascher’s, and lastly Lauba’s. Lauba’s cadenza can be overwhelming for some less experienced players; the author feels it should not be attempted until the player has attained the facility to effectively perform it. Lauba's saxophone works, becaue they push the limits of the performers and the instrument, are very difficult and only the most advanced players perform them; as a result many players do not play them at all. However, most every saxophonist will study Glazunov's Concerto and might

\footnotetext{
${ }^{61}$ Alexander Glazunov and Erland von Koch, Music Minus One Alto Saxophone, Glazunov/von Koch: Concertos in E-Flat Major (Elmsford, NY: Music Minus One, 2000).
} 
eventually learn all of the cadenzas. By including Lauba's cadenza in the scope of study of Glazunov's work, the next generation of saxophonists will be challenged to be more technically advanced.

With the presence of Lauba's alternate cadenza, the possibility of other composers and saxophonists writing their own cadenzas is not unlikely. Indeed, this process has been documented in this paper: Rascher wrote his own cadenza because he was not satisfied with Glazunov's and Douglas O’Connor has composed an alternate ending to Lauba's cadenza because he did not feel Lauba's most effectively drew in the orchestra. Since the Concerto is a standard work which is performed frequently, the composition of another alternate cadenza is a realistic possibility.

There is no doubt that Glazunov's Concerto will continue to be a very important standard in the classical saxophone repertoire; it is a requirement for every serious saxophonist. Since its composition, it has been one of the most frequently performed saxophone pieces. With the new performance possibilities that have recently become available, the author expects that performances of the work will increase as saxophonists begin to look again at the Concerto and program it in order to incorporate these new resources. In addition, there will be more variance in the many performances of the work as saxophonists reconsider their approaches to it and subsequently teach the piece to their students.

For the past seventy-five years, the Leduc edition of Glazunov's Concerto has been the sole version that saxophonists have used. However, with the new scholarly edition by Bärenreiter, the French edition by Leduc, and the Christian Lauba alternate cadenza, new possibilities for performance and interpretation can now be readily explored. These resources aid saxophonists in obtaining a firm understanding of the work and its development. In addition 
to performance practice, Bärenreiter’s edition provides a clear account of the historical background relating to Glazunov's work. It is the hope of the author that this research, which addresses many important aspects of the Concerto, will assist in reinvigorating this wellestablished work by providing a single, comprehensive source. 


\section{Appendix}

Variance in Slur Placement in Measures 179 through the Downbeat of measure 189

Measure 180 the last eighth note of beat three - quarter note on beat one of measure 181 Leduc Edition:



Bärenreiter Edition:

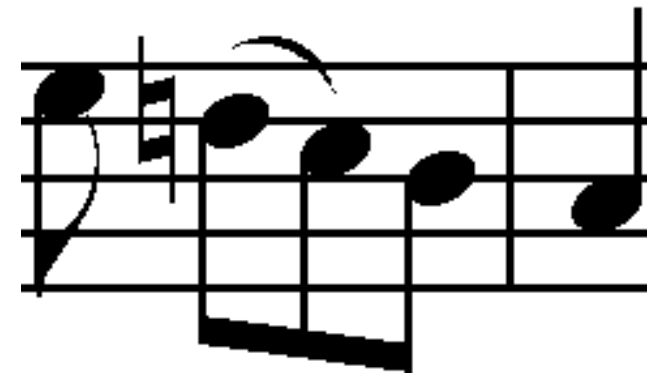

Measure 181 beat four - quarter note on beat one of measure 182 Leduc Edition:

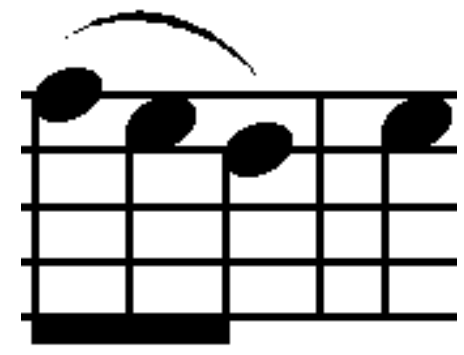

Bärenreiter Edition:




Measure 182 last eighth note of beat four - measure 183 the second eighth note Leduc Edition:

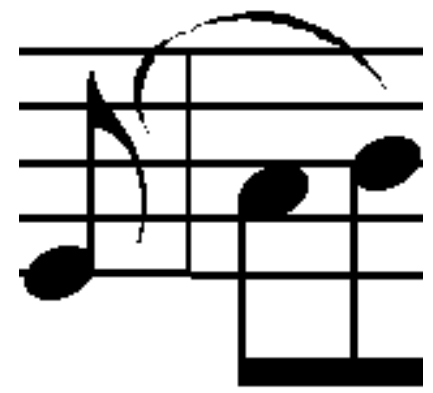

Bärenreiter Edition:

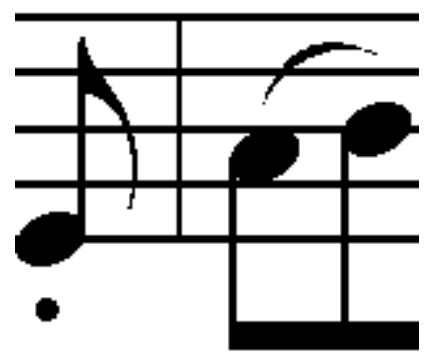

Measure 183 the last eighth note - measure 184 the second eighth note Leduc Edition:



Bärenreiter Edition:

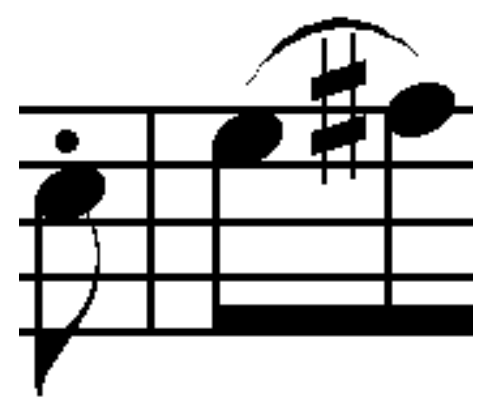


Measure 184 beats two and three

Leduc Edition:

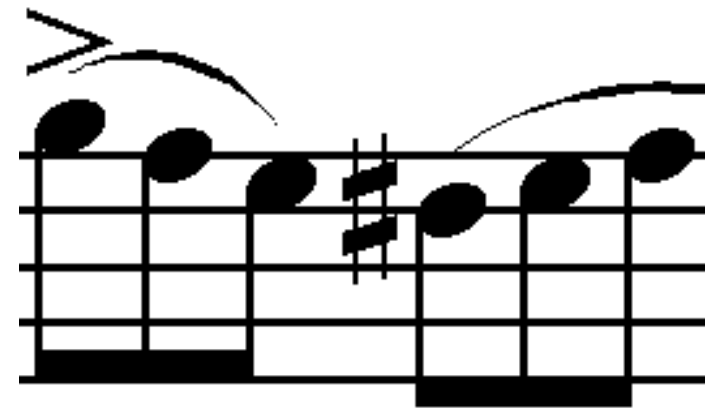

Bärenreiter Edition:

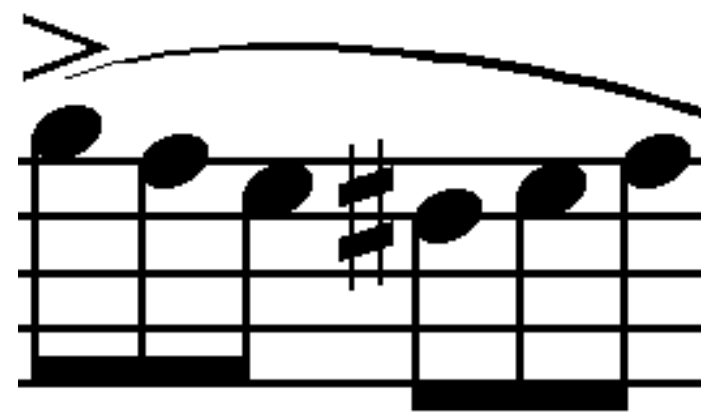

Measure 186 beat four - measure 187 beat one Leduc Edition:

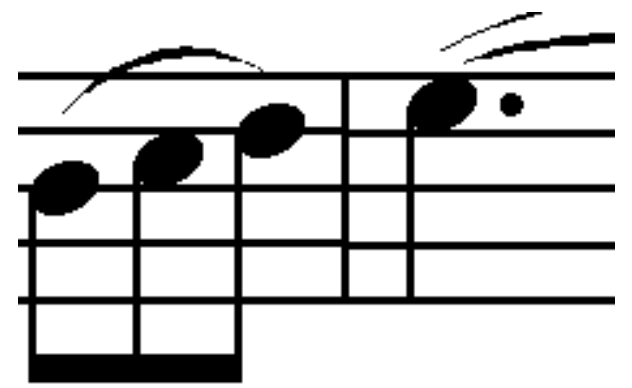

Bärenreiter Edition:




Measure 188 - the downbeat of measure 189

Leduc Edition:

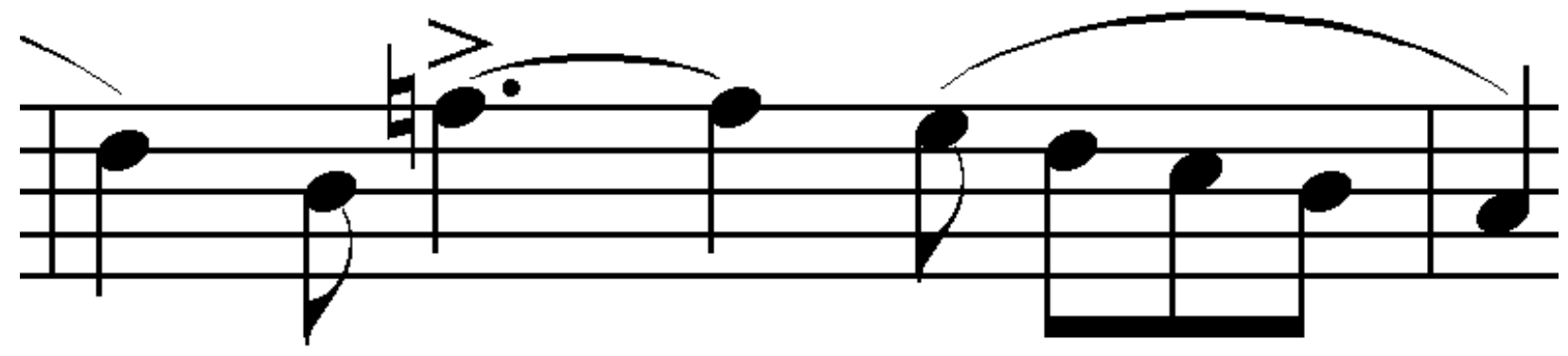

Bärenreiter Edition:

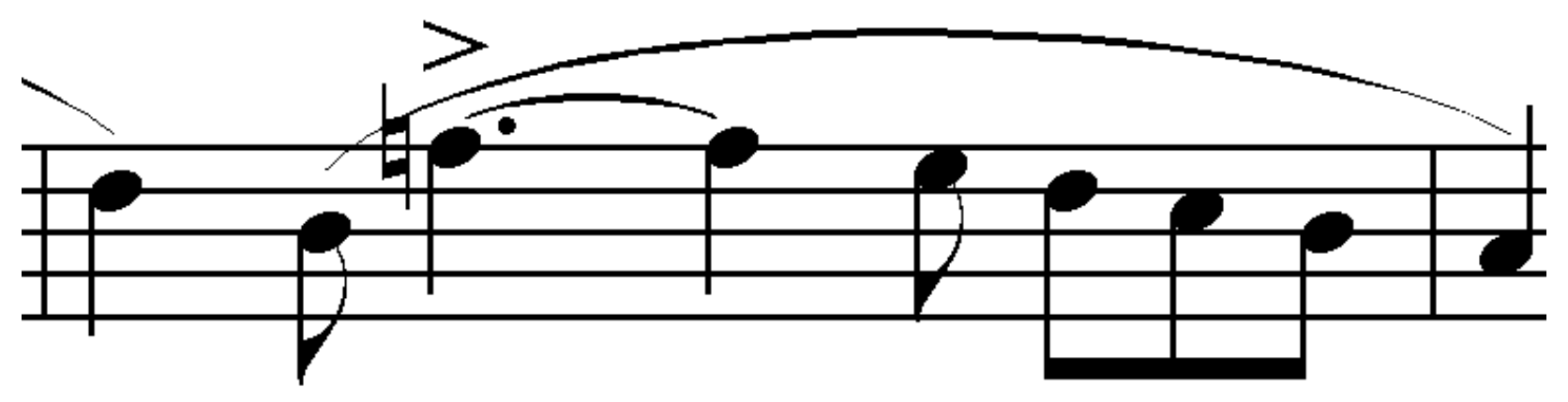




\section{Bibliography}

Charles, Jacques. "Dossier Glazounov.” Translated by Bernard Savoie. Saxophone Symposium Volume XIII No. 3 (Summer 1988): 18-29.

Duke, Stephen R. "A Structural Analysis of the Concerto for Alto Saxophone and String Orchestra in E flat Major, Op. 109 with Suggested Performance Application.” MM document. University of North Texas, 1981.

Glazounov, Alexander, and A. Petiot. Concerto en mi bémol pour saxophone alto avec accompagment de piano. Paris: Alphonse Leduc, 1936.

Glazunov, Alexander and Erland von Koch, Music Minus One Alto Saxophone, Glazunov/von Koch: Concertos in E-Flat Major. Elmsford, NY: Music Minus One, 2000.

Glazunov, Alexander. Concerto for Alto Saxophone and String Orchestra, Op. 109. Kassel, Germany: Barenreiter, 2010.

Lauba, Christian. Cadence du Concerto pour Saxophone et orchestre à cordes d'Alexandre Glazounov: $13^{e}$ étude de style pour saxophone alto. Paris: Alphonse Leduc, 2010

Lauba, Christian, e-mail message to Christopher D. Mickel, 25 January 2011. Personal collection of Christopher D. Mickel. Fairmont, West Virginia.

Liley, Thomas L. "A Teacher's Guide to the Interpretation of Selected Music for Saxophone." D.M. diss., Indiana University, 1988.

Londeix, Jean-Marie. HELLO! Mr. Sax. Paris: Editions Musicales Alphonse Leduc, 1989.

O’Connor, Douglas. “Ending to Lauba’s Glazunov Cadenza.” Score. 2010. Personal collection of Douglas O’Connor. Rochester, New York.

O’Connor, Douglas, e-mail message to Christopher D. Mickel, 14, January 2011. Personal collection of Christopher D. Mickel. Fairmont, West Virginia.

Rascher, Carina, e-mail message to Christopher D. Mickel, 28 May 2010. Personal collection of Christopher D. Mickel. Fairmont, West Virginia.

Rascher, Carina, e-mail message to Christopher D. Mickel, 23 January 2011. Personal collection of Christopher D. Mickel. Fairmont, West Virginia. 
Rascher, Sigurd M. "Alexander Glazounov: Concerto pour Saxophone Alto avec l'orchestre de cordes.” Saxophone Symposium Volume XIII No.2 (Spring 1988): 16-19.

Smialek, Thomas. "The Structure and Style of Alexander Glazunov's Concerto in E-flat for Alto Saxophone and String Orchestra, Op. 109." Saxophone Symposium Volume XX No. 4 (Winter 1995): 15-21.

Sobchenko, André. "Letters from Glazunov: ‘The Saxophone Concerto Years'.” The Saxophone Journal (September/October 1997): 66-70.

Umble, James C, ed. “Concerto in E flat (1934) (15’) for Alto Saxophone and String Orchestra by Alexandre Glazounov (1865 - 1936) Editions Leduc.” In Jean-Marie Londeix: Master of the Modern Saxophone. Cherry Hill, NJ: Roncorp Publication 2000. 